ORIGINAL ARTICLE

\title{
Magnetic Resonance Imaging of Pelvis: A One-stop Shop Modality for the Staging of Carcinoma of Cervix
}

\author{
Ajit D Karambelkar ${ }^{1}$, Rishabh D Bora ${ }^{2}$
}

\begin{abstract}
Aim and objective: Magnetic resonance imaging (MRI) of pelvis as a one-stop shop modality for locoregional staging of carcinoma of the cervix. Compare the MRI staging with the clinical staging of the carcinoma of the cervix.

Materials and methods: We conducted pelvic MRI examinations on histological proved 83 cases of cervical carcinoma on MRI 1.5 T scanner.

Results: Magnetic resonance imaging demonstrated cervical mass in 79 out of 83 (95\%) patients. No mass lesion was demonstrated in 4 out of 83 patients, who were clinically diagnosed as stage I. $X^{2}$ test demonstrated $X^{2}$ value of 43.6 and $p$ value $<0.01$ indicating a significant difference between staging by staging by MRI and that by clinical staging. Z score test also showed a significant difference in staging by MRI and that by clinical staging for stages IB, IIB, IIIB, and IVA with a $p$ value $<0.05$. The Z score (RD) was maximum for stage IIIB and minimum 0.034 for stage IIIA, suggesting that the greatest difference was observed in stage IIIB. We could not find any significant difference for stage IIIA, IA and stage IIA.

Conclusion: Magnetic resonance imaging is superior to clinical staging of the carcinoma of the uterine cervix in stage IB, IIB and IVA. Magnetic resonance imaging has an excellent ability to demonstrate the locoregional extent of the tumor. Hence, it should be used as a one-stop shop modality for the staging of cervical carcinoma.
\end{abstract}

Keywords: Carcinoma, Cervix, Magnetic resonance imaging, Staging.

Journal of South Asian Federation of Menopause Societies (2020): 10.5005/jp-journals-10032-1193

\section{INTRODUCTION}

Invasive cervical cancer is the most common genital female malignancy worldwide. $78 \%$ of invasive cervical cancer typically affects younger females of developing countries. ${ }^{1,2}$

The invasive cervical cancer is diagnosed at an advanced stage and a major cause of death in Indian women. ${ }^{3}$

There is forty percent expected rise in the number of patients of carcinoma of the cervix from the year 2005 to 2010 in developing nations like India. ${ }^{4}$ Annual crude incidence rate of carcinoma cervix in India is 26.2 and annual crude mortality rate is 14.7 per 100,000 female in India. ${ }^{5}$ Cervical cancer causes the highest individual loss of life years due to cancer. ${ }^{6}$ In India, more than 200 women die every day because of cancer of the cervix.,

Cervical carcinoma in situ (CIN) is generally detected in women aged 25-34 years. Invasive cervical carcinoma is the most often diagnosed in women older than 50 years. ${ }^{9}$

Cancer of the cervix is staged in accordance with the modified classification of the International Federation of Gynecology and Obstetrics (FIGO). ${ }^{10,11}$

Federation of Gynecology and Obstetrics classification consists of clinical examination which includes a cystoscopy, proctoscopy, barium enema, intravenous urography, chest-X-ray and examination under anesthesia. Clinical staging is limited by intrinsic deficiencies in the detection of the invasion of the parametrium and pelvic side walls, and the accurate size of the tumors. It also ignores the lymph node status, which is the most important prognostic factor in all stages. ${ }^{12}$

Clinical staging also shows error rates of 17 to $32 \%$ with stage IB disease and up to $67 \%$ with stages II to IV disease when compared with intraoperative and pathological findings. Pelvic or para-aortic lymph node metastases are in most patients by clinical staging. The extension to the urinary bladder or adjacent bowel is also difficult to determine clinically. ${ }^{12-18}$

\begin{abstract}
${ }^{1}$ Department of Radiology, Government Medical College, Aurangabad, Maharashtra, India

${ }^{2}$ Department of Radiology, Bharati Hospital, Pune, Maharashtra, India Corresponding Author: Ajit D Karambelkar, Department of Radiology, Government Medical College, Aurangabad, Maharashtra, India, Phone: +17185777948, e-mail: ajit.k@outlook.com
\end{abstract}

How to cite this article: Karambelkar AD, Bora RD. Magnetic Resonance Imaging of Pelvis: A One-stop Shop Modality for the Staging of Carcinoma of Cervix. J South Asian Feder Menopause Soc 2020;8(1):7-23.

Source of support: Nil

Conflict of interest: None

These shortcomings coupled with the emergence of newer treatment options have encouraged the incorporation of computed tomography (CT) and MRI in the staging of the cervical cancer patients. ${ }^{19}$

Computed tomography with intravenous contrast has limited ability to accurately detect local tumor extent and stromal invasion. ${ }^{20,21}$

Ultrasonography is valuable for assessment of the urinary obstruction in advanced disease. Ultrasound examination has several limitations including the patient's habitus, operator dependence, and low signal-to-noise ratio, and low contrast resolution. The transvaginal and transrectal ultrasonography is of limited utility in the staging of cervical cancer. ${ }^{10,22}$

Recently MRI is has become the mainstay of the radiologic evaluation of the pelvis. Although sonography and CT are less susceptible to image degradation by motion than is MRI, the limited effect of cardiac and respiratory motion on the pelvis minimizes this disadvantage of MRI, also the versatility of MRI scanning planes is a significant advantage over CT. It is the capability of MRI to 
distinguish normal from abnormal tissue is more important than image degradation and scanning planes. $^{23,24}$

Clinical staging remains the standard of reference for treatment protocol selection even though in large measure because of the avoidance of sophisticated diagnostic tool clinical staging poorly correlates with surgical and pathologic staging.

The MRI can identify between the early disease (I and IIA) that can be treated by surgery and stages beyond IIA by radiation or combined chemoradiation.

The MR Imaging has the potential for improving work up and prognosis at all stages. So in the present study, we will be studying the role of MRI in cervical malignancy as MRI has the ability to stage the cervical malignancy and has potential to change the therapeutic approach, the overall cost to patient and medical system. ${ }^{25-27}$

\section{Materials and Methods Inclusion Criteria \\ Every patient referred for MRI for staging Ca cervix.}

\section{Exclusion Criteria}

Implanted electrical devices, pacemaker, defibrillator, neurostimulator, and cochlear implants.

\section{Extreme Claustrophobia}

Each of 83 patients with no contraindication to MRI and histopathologically proven cervical carcinoma referred from the Department of Obstetrics and Gynecology underwent MRI examination from Dec 2008 to Nov 2010 in the Department of Radiodiagnosis.

The MRI examination was carried out after written and informed valid consent from the patient and her relatives on a 1.5 tesla scanner. XL TORSO 8 channel coil was used. The images were read by two radiologists and when there was disagreement, the opinion of more experienced radiologist was considered.

Clinical findings were not provided to the radiologists before the MRI staging of cervical malignancy was done.

\section{Magnetic Resonance Imaging Protocol}

Patients were directed not to have food for 4-6 hours before the $\mathrm{MRI}$ examination to limit artifacts from bowel movements. Overdistended urinary bladder causes ghosting and motion artifacts on T2-weighted images. Hence, patients emptied the urinary bladder before the examinations.

Patients were scanned in the supine position. A pelvic surface array multichannel coil was used. $5 \mathrm{~mm}$ thickness non-fat-saturated high-resolution T1, T2 weighted and fat saturated T2 weighted sequences in axial, coronal and sagittal plane were obtained from the lower pole of the kidneys to the vulva.

Noncontrast MR urography sequences were obtained when ureteric involvement was seen on other sequences.

\section{Magnetic Resonance Imaging Criteria for Staging of Cervical Carcinoma Tumor}

In general, cervical carcinoma is better defined at T2-weighted imaging. Normal fibrous stroma of the cervix has low signal on T2 weighted imaging.
On T2-weighted imaging the cervical carcinoma has intermediate signal intensity. The tumor can be exophytic, infiltrating, or endocervical with a barrel shape. Magnetic resonance imaging shows disruption of the low signal fibrous stroma by intermediate to high signal cervical mass on T2 weighted imaging. After gadolinium-based intravenous contrast administration tumor shows enhancement.

In older individuals, the tumor is endophytic. The tumor tends to be exophytic in younger patients. Cervical cancer is centered in the level of the cervix. Then, it invades the adjacent structures or protrudes into the vagina. An endometrial polyp or adenocarcinoma is centered in the endometrial cavity and protrudes into the endocervical canal. Prolapsed submucous fibroids are distinctly more hypointense at T2-weighted imaging than cervical carcinomas. ${ }^{15,28}$

It is important to accurately determine the size of the tumor. Surgery is preferred if the size is less than $4 \mathrm{~cm}$. The MRI measurements are valid in most cases with the macroscopic size of the tumor. ${ }^{29}$ However; the size of the tumor can be overestimated due to inflammation or edema. ${ }^{30}$ The morphology and extent of spread are important for mapping the brachytherapy. ${ }^{31}$

\section{Vagina}

Hyperintense mass causing interruption of the hypointense vaginal stroma on T2-weighted imaging is compatible with vaginal invasion. Invasion of the lower one-third of the vagina increases the stage and signifies the modification of the strategy for radiation therapy.

\section{Parametria}

Intact hypointense fibrous stroma at T2-weighted imaging essentially excludes parametrial invasion. Parametrial invasion is suspected if the normal cervical stroma is infiltrated and hyperintense T2 signal surrounds the tumor. Peritumoral inflammatory tissue can have a similar appearance and can be confused with the parametrial invasion. The contrast-enhanced study can be helpful in such cases. Tumor enhances immediately after contrast administration while edema and inflammatory tissue show delayed enhancement. The signal abnormality in parametrium similar and contiguous with the cervical tumor is compatible with parametrial invasion. Surgery is contraindicated if there is a parametrial invasion. ${ }^{4,15,32,33}$

\section{Pelvic Wall}

Pelvic sidewall invasion is considered when the tumor involves the pelvic musculature, with or without a hydroureter.

\section{Bladder and Rectum}

Bladder or rectal invasion is present when disruption of their normal hypointense walls is seen at T2-weighted imaging, with or without a mass protruding into the lumen. ${ }^{7,8}$ Dynamic gadoliniumenhanced T1-weighted sequences are helpful for confirming invasion and identifying fistulous tracts. Hyperintense thickening of the bladder mucosa at T2-weighted imaging indicates edema and is not a direct sign of invasion. However, this "bullous edema sign" of the posterior wall mucosa should be analyzed carefully for any associated nodulation suggestive of tumor. ${ }^{14,15,34,35}$

\section{Lymph Nodes}

MRI demonstrates lymph nodes as intermediate signal intensity structures. These can be easily identified on MRI. The typical shape 
and signal easily distinguish them from muscles and vascular structure. $10 \mathrm{~mm}$ size cut off in the short axis is considered as nodal involvement. Lymph node measuring less than $10 \mathrm{~mm}$ in transverse dimension is also considered involved if it has irregular shape and/ or central necrosis. ${ }^{34,36,37}$

Falsely positive nodal involvement can be seen with reactive inflammatory nodal enlargement.

\section{Observation}

We conducted a study of 95 patients with 1.5 T MRI. Eighty-three subjects were diagnosed with cervical carcinoma pathologically. Rest 12 patients were previously treated.

The MRI demonstrated hyperintense area in 79 out of 83 (95\%) patients corresponding to the cervical mass lesion which was seen as a hyperintense mass lesion on $\mathrm{T} 2 \mathrm{~W}$ images and hypointense on T1W images.

There was no demonstrable mass lesion seen on MRI or any hyperintense area in the uterine cervical region in 4 out of 83 patients who were clinically diagnosed as stage I.

There was hypointense signal intensity seen in 10 of 12 patients who had taken radiotherapy 1 year back and referred to rule out any recurrence. We found that in only two cases there was no obvious hypointense signal noted.

There were only 2 cases in the second decade with a steep rise to 18 cases in the 3 rd decade. Then there was a steady increase from 24 cases in the 4 th decade to reach a maximum of 30 cases in the 6th decade and a sharp fall in the 7th decade with only 2 cases. Here we observed a typical demographic presentation of the carcinoma of cervix and peak of the disease observed in 5th and 6 th decade of life (Table 1).

Table 1: Agewise distribution of cases

\begin{tabular}{lc}
\hline Age group & No. of patient \\
\hline $20-29$ & 2 \\
$30-39$ & 15 \\
$40-49$ & 16 \\
$50-59$ & 21 \\
$60-69$ & 27 \\
$70-80$ & 2 \\
Total & 83 \\
\hline
\end{tabular}

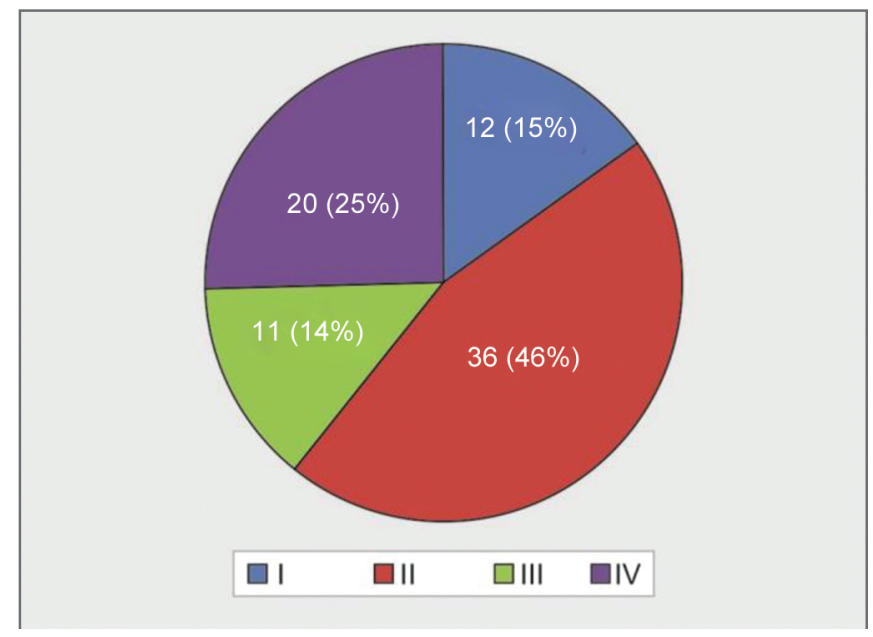

Fig. 1: Graphical representation of stagewise distribution
Maximum no of patients of cervical carcinoma harbored stage II disease and it constituted almost $46 \%$ of total patients. The stage IV disease was seen in 20 patients with $25 \%$ of cases. Out of the total 79 cases diagnosed on MRI, stage I and stage III disease represented 32 cases i.e., $29 \%$ of total cases. MRI has diagnosed 36 cases of stage II that is almost three times the no of cases it was diagnosed as stage I or stage III disease (Table 2 and Fig. 1).

Highest 10 cases were observed in the age group 30-39 and 50-59. These patients had stage II and stage IV disease respectively. Stage II disease occurs more frequently in 30-39 year age group. Stage IV disease occurred in 50-59 year age group (Table 3 and Fig. 2).

Stage IB is defined as a clinically visible disease which is again divided into stage IB1 is a demonstrable mass of $4.0 \mathrm{~cm}$ or less in greatest dimension. Stage IB2 A is mass more than $4.0 \mathrm{~cm}$ in greatest dimension (Figs $3 \mathrm{~A}$ to $\mathrm{C}$ ).

Nine cases had stage IB2 disease. Three cases had stage IB1 disease. MRI diagnosed stage IB2 cases three times more than stage IB1 (Figs 3D, 4 and 5A).

Table 2: Stagewise distribution

\begin{tabular}{ll}
\hline Stage & No. of points \\
\hline I & 12 \\
II & 36 \\
III & 11 \\
IV & 20 \\
Total & 79 \\
\hline
\end{tabular}

Table 3: Stage- and agewise distribution

\begin{tabular}{lrrrr}
\hline & \multicolumn{3}{c}{ Stage } \\
\cline { 2 - 5 } Age group & $I$ & \multicolumn{1}{c}{$I I$} & \multicolumn{1}{c}{1} & \multicolumn{1}{c}{ I } \\
\hline $20-29$ & 2 & 0 & 1 & 1 \\
$30-39$ & 1 & 10 & 2 & 1 \\
$40-49$ & 5 & 8 & 4 & 10 \\
$50-59$ & 1 & 8 & 3 & 4 \\
$60-69$ & 3 & 9 & 0 & 1 \\
$70-80$ & 0 & 1 & 11 & 20 \\
Total & 12 & 36 & &
\end{tabular}

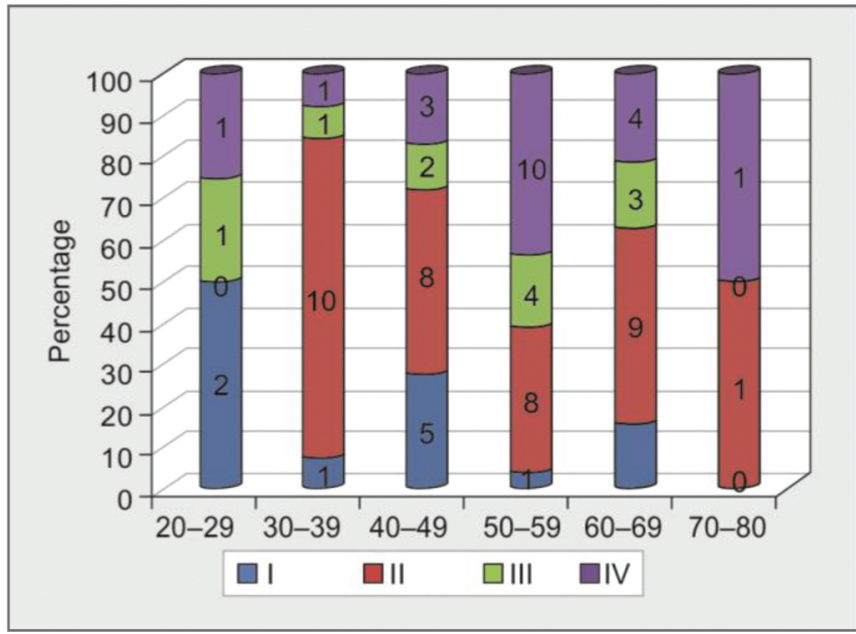

Fig. 2: Graphical representation of stage- and agewise distribution 

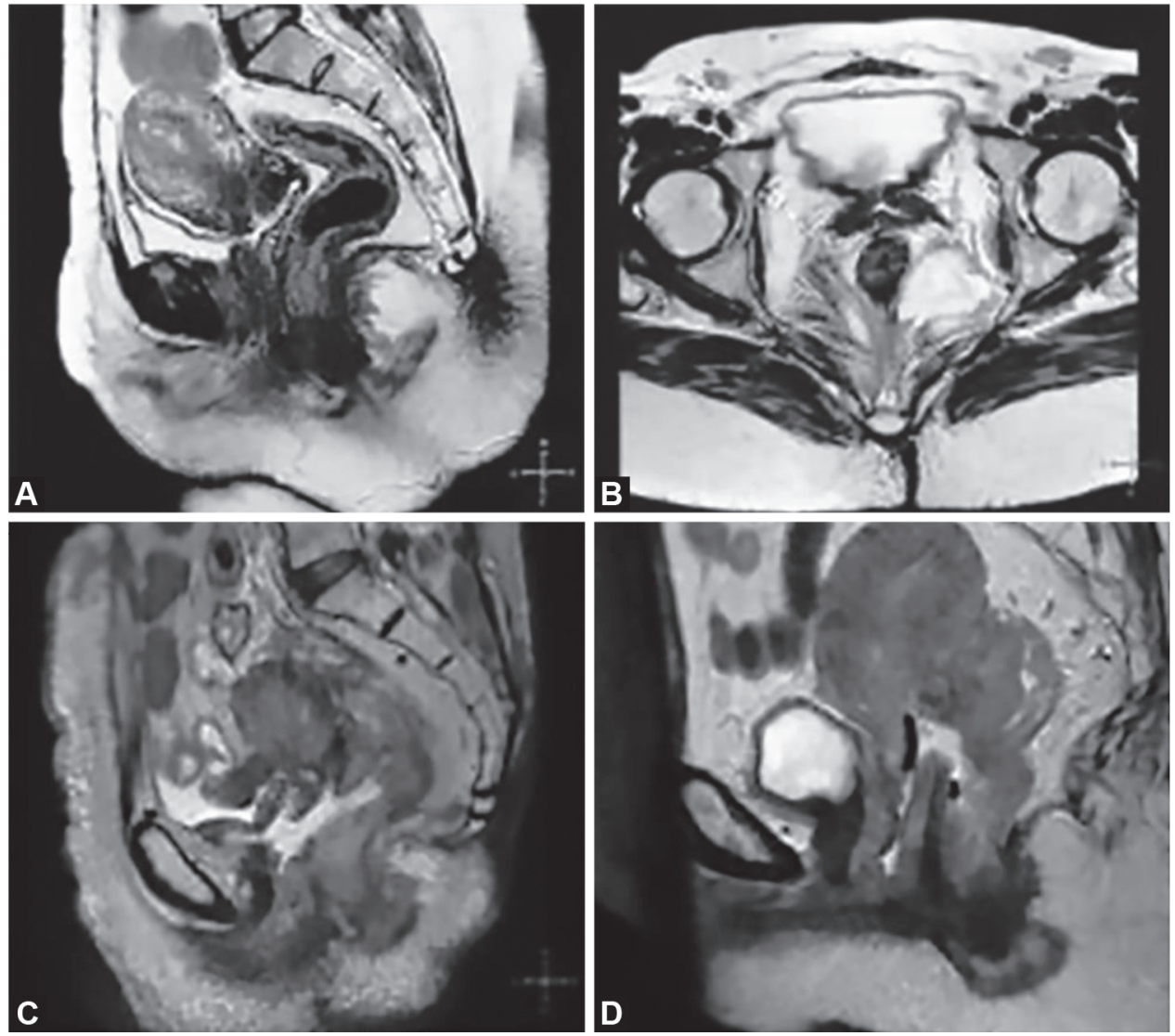

Figs 3A to D: (A) T2W sagittal vesicovaginal fistula; (B) T2W axial vesicovaginal fistula; (C) T2W sagittal rectovaginal and vesicovaginal fistula; (D) T2W sagittal rectovaginal fistula
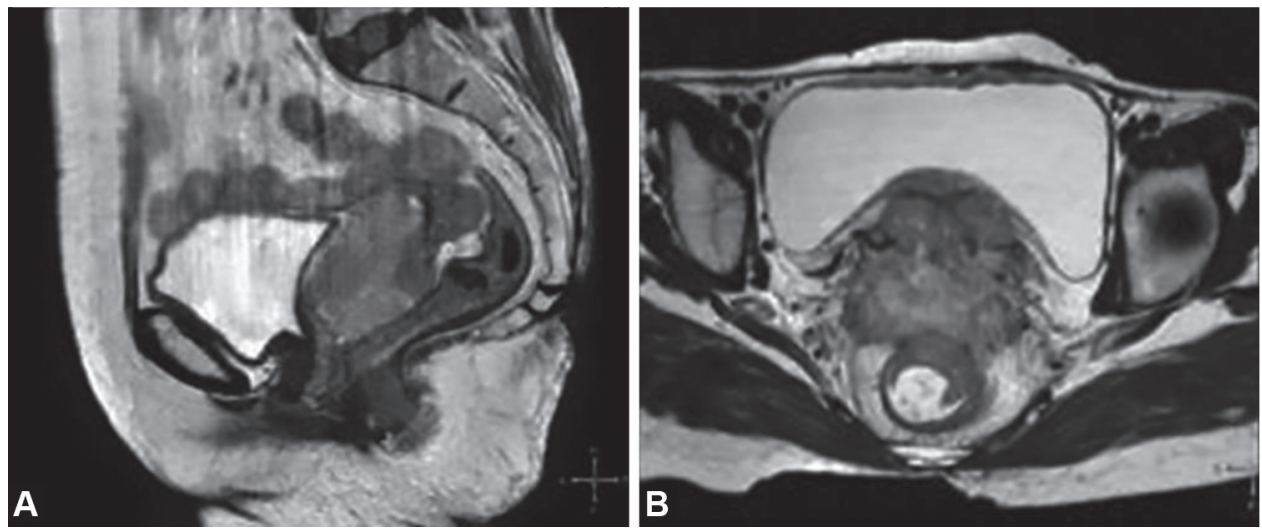

Figs 4A and B: (A) T2W sagittal lower vaginal invasion; (B) T2W axial rectal invasion

An MRI has more diagnostic performance in a staging of stage IB2 disease than stage IB1 (Table 4, Fig. 6).

In stage IIA, the tumor does not invade lower one-a third of the vagina. There can be a uterine invasion. There is no parametrial invasion. In stage, IIB tumor invades parametrium but does not reach the pelvic side wall.

We used the same criteria and observed focal invasion of the cervical stromal ring in 31 (81\%) of total 38 stage II patients with parametrial invasion and hence staged as stage IIB. Upper vaginal invasion is seen in $9(23 \%)$ of 38 patients so they were staged as stage IIA. The stage IIB patients were considerably larger in number as opposed to stage IIA (Figs 5B to D for IIA and Figs 7 and 8 A for IIB).

The tumor extends to the pelvic side wall in stage IIIB. Tumor causing hydronephrosis or a nonfunctioning kidney on the same side of the parametrial invasion is also considered stage IIIB (Figs $8 \mathrm{~B}$ to $D, 9 A$ and $B$ ).

Ten of 79 patients staged as IIIB on findings based on MRI, 7 (70\%) patients had bilateral or unilateral hydronephrosis and only 3 patients had (30\%) lateral pelvic wall invasion. So our study shows that there are significantly more cases diagnosed as stage IIIB 

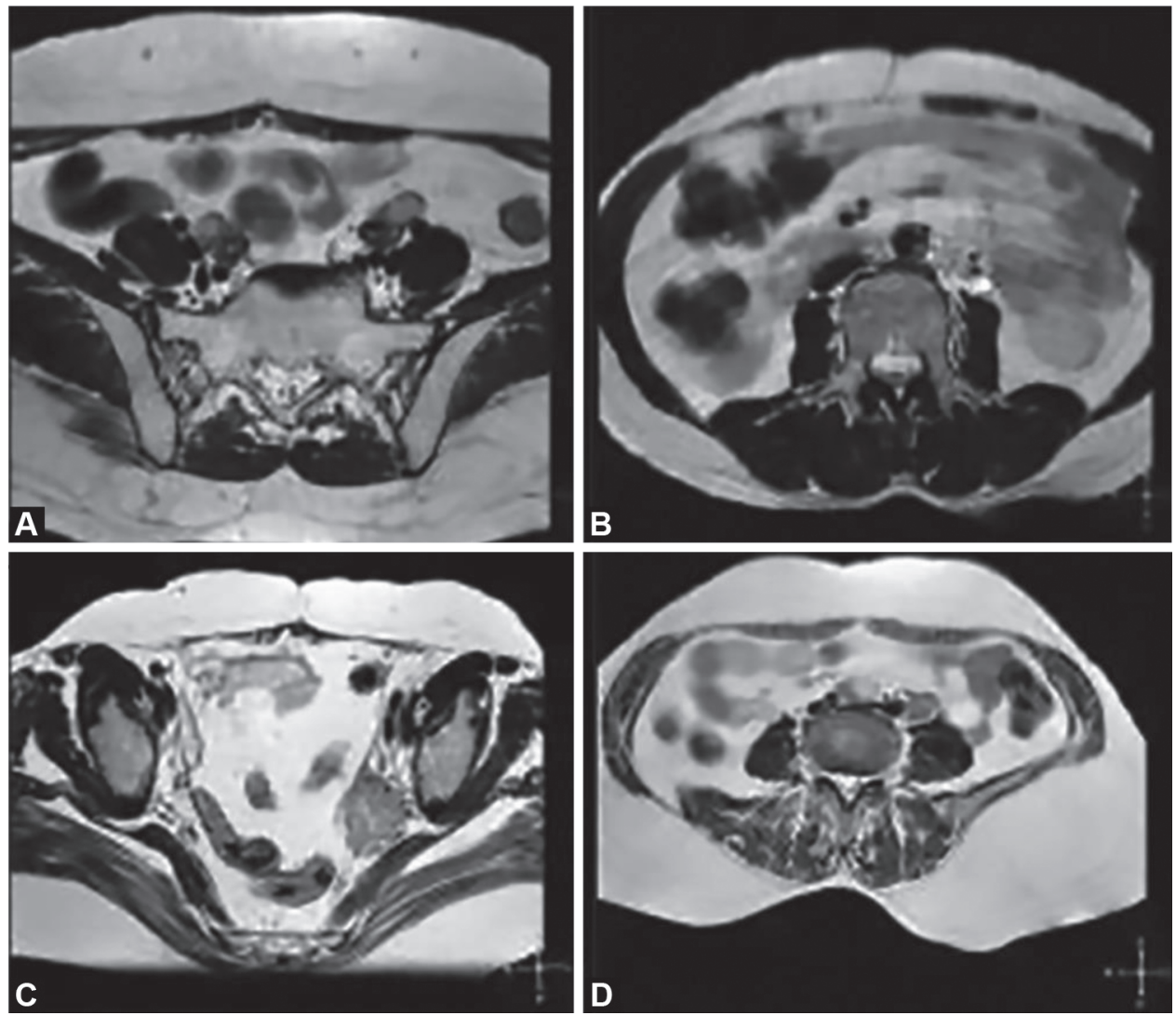

Figs 5A to D: (A) T2W axial bilateral iliac lymph nodes; (B) T2W axial left periaortic lymph nodes; (C) T2W axial left internal iliac lymph nodes; (D) T2W axial left common iliac lymph node

Table 4: Stage IB

\begin{tabular}{lc}
\hline Stage & No. of patients \\
\hline IB1 & 3 \\
IB2 & 9 \\
Total & 12 \\
\hline
\end{tabular}

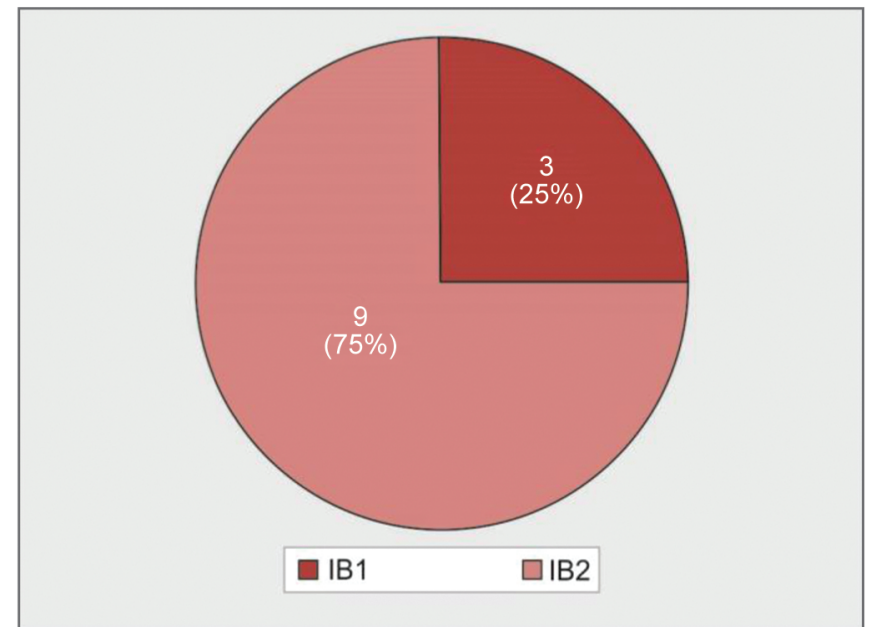

Fig. 6: Graphical representation of stage IB

due to the involvement of ureters than lateral pelvic wall invasion (Table 5 and Fig. 10).

According to the FIGO classification stage, IVA disease is defined as tumor invasion of bladder or rectal mucosa, which
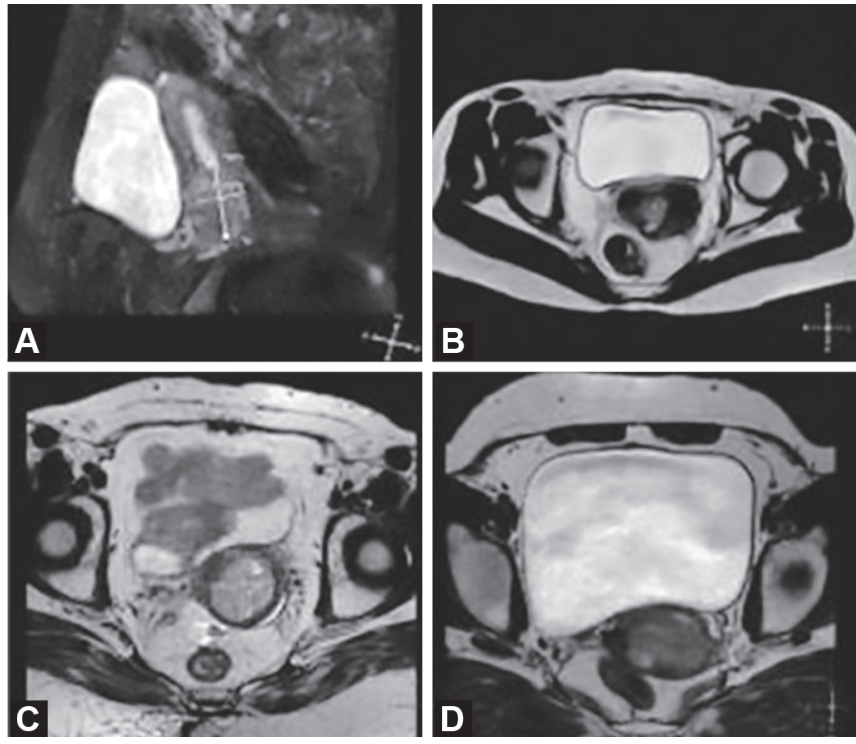

Figs 7 A to D: (A) T2W sagittal fat saturation; (B) T2W axial; (C and D) T2W axial intact cervical hypointense stromal ring

can be detected by cystoscopy and sigmoidoscopy with the aid of biopsy.

We found $3(15 \%)$ cases of bladder invasion 4 cases of rectal invasion and (20\%) 13 cases in which both bladder and rectal invasion was present (Table 6 and Figs 9C, 11 and 12).

The most important prognostic indicator is lymph node involvement. The lymph node with size $\geq 10 \mathrm{~mm}$ is positive for metastatic involvement. 

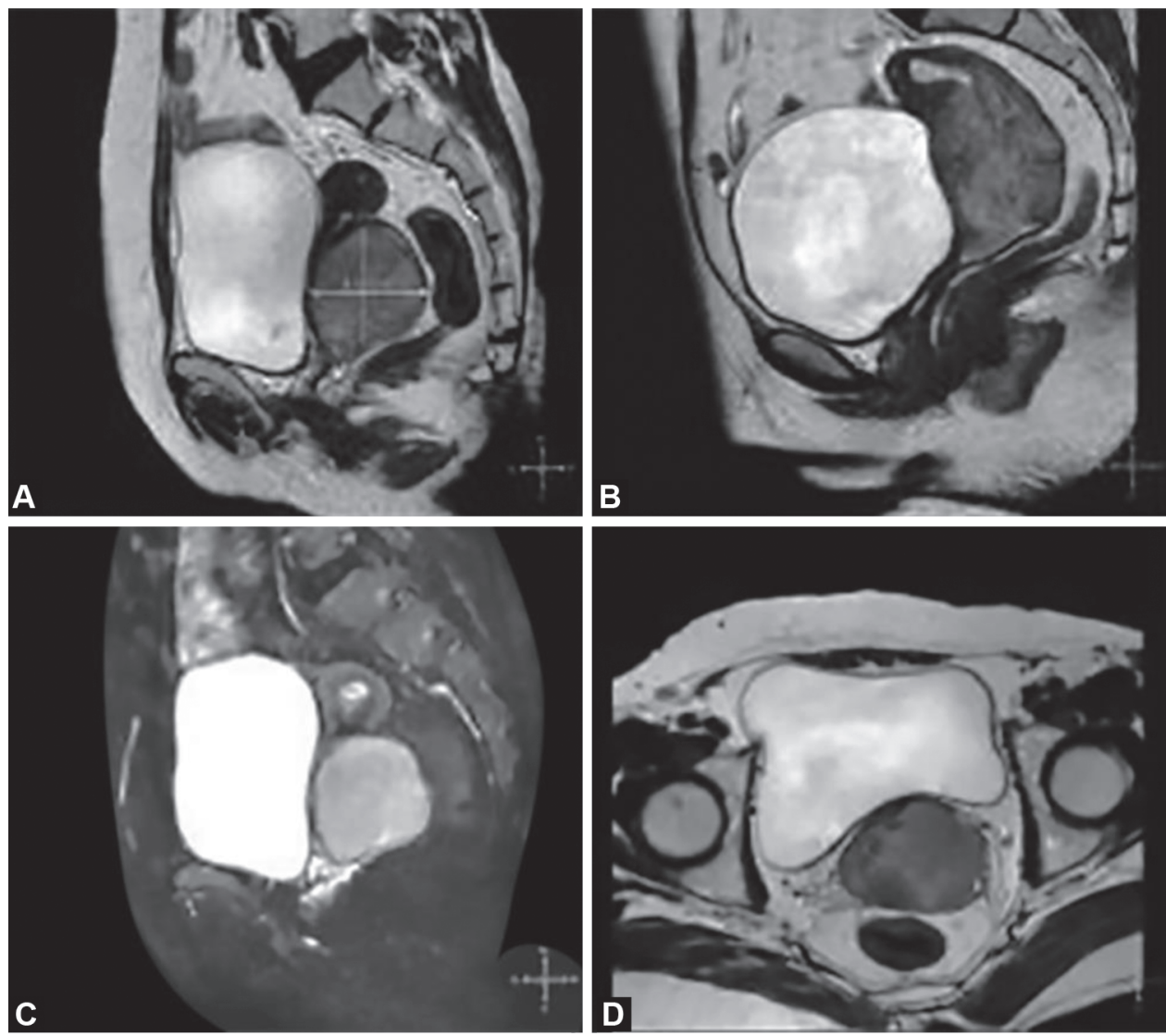

Figs 8A to D: (A) T2W sagittal; (B) T2W sagittal; (C) T2W sagittal fat saturation; (D) T2W axial
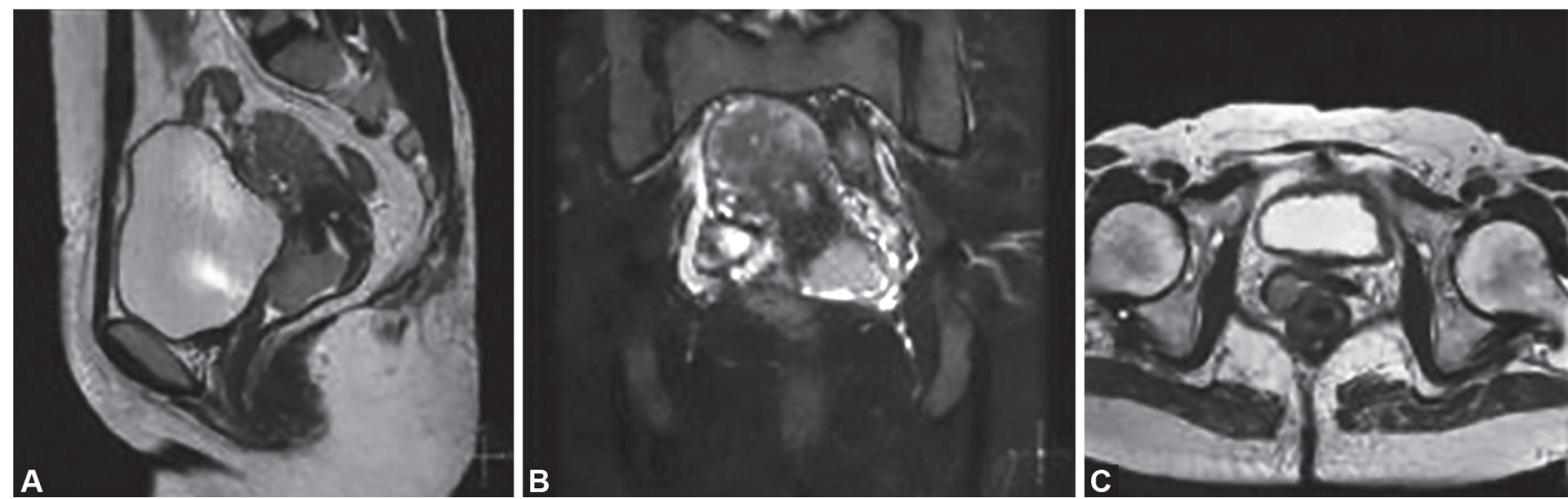

Figs 9A to C: (A) T2W sagittal; (B) T2W coronal fat saturation; (C) T2W axial

We were able to demonstrate significant no of patients having abdominal and periaortic lymphadenopathy. There is a gradual increase in the no cases showing lymphadenopathy from stage I to stage IV disease. The highest no of cases was seen in stage IV disease with a maximum of 20 cases (Table 7 and Fig. 13).

We had 33 patients of lymphadenopathy and maximum no of cases was seen in stage IVA disease. In most of the cases, the lymph nodes involved were the iliac nodes seen in 28 patients and 19 of 28 patients had unilateral involvement of iliac lymph nodes. In 9 cases there was bilateral iliac nodal enlargement (Table 8 and Fig. 14). There were 5 cases in which periaortic lymph node enlargement was seen, including 2 cases of stage II, 1 case of stage III and 2 cases of stage IV. There was a single case in which we also found enlargement of perirectal lymph nodes (Table 9 and Figs $15,16 \mathrm{~A}$ and 17).

Significant no of cases of cervical carcinoma invading the uterine body is seen, with a total of $26(30 \%)$ from 83 patients. A single case of uterine body invasion was seen in stage IIA disease whereas stage IB and IIB showed 3 cases each. There is a rise in cases in stage IIIB to 5 with no single case seen in stage IIIA. However, there is a sudden increase in the no of cases of uterine invasion in stage IV with maximum 14 cases (Table 10 and Figs 16B to D, 18A and 19). 


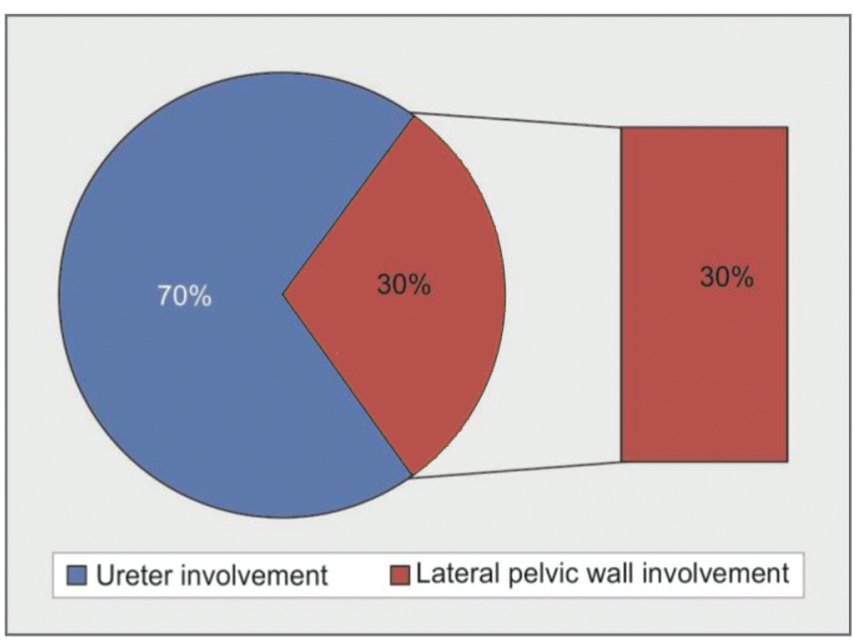

Fig. 10: Graphical representation of stage IIIB
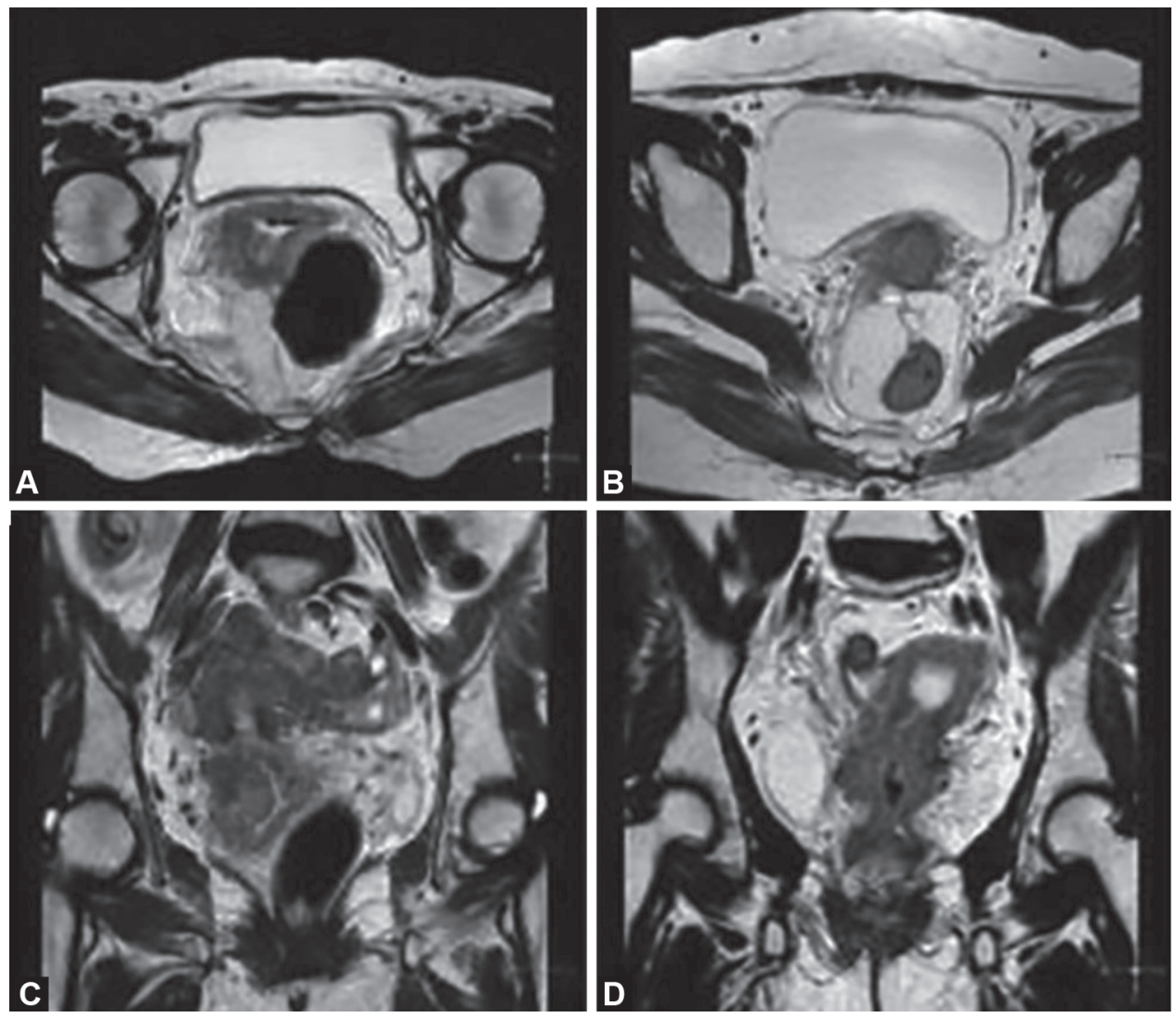

Figs $11 \mathrm{~A}$ to D: (A) T2W axial; (B) T2W axial; (C) T2W coronal; (D) T2W coronal

MRI has a distinct advantage in showing fistulous communication due to its inherent high contrast resolution. The fistulous communications were seen as a hyperintense tract on $\mathrm{T} 2 \mathrm{~W}$ images and were clearly demonstrated without the use of contrast material. We observed 7 cases of fistula out of total 95 cases. All cases of fistula had stage IV disease. Out of a total of seven cases, four had a recto-vaginal fistula, two had a vesicovaginal fistula and one case had both vesicovaginal and rectovaginal fistula. (Table 11 and Figs $18 \mathrm{~B}$ and C, 20 and 21)
Table 5: Stage IIIB

\begin{tabular}{lc}
\hline Involvement & No. of patients \\
\hline Ureter involvement & 7 \\
Lateral pelvic wall involvement & 3 \\
Total & 10 \\
\hline
\end{tabular}

Table 6: Stage IVA

\begin{tabular}{lc}
\hline Involvement & No. of patients \\
\hline Urinary bladder & 3 \\
Rectum & 4 \\
Both urinary bladder and rectum involvement & 13 \\
\hline
\end{tabular}



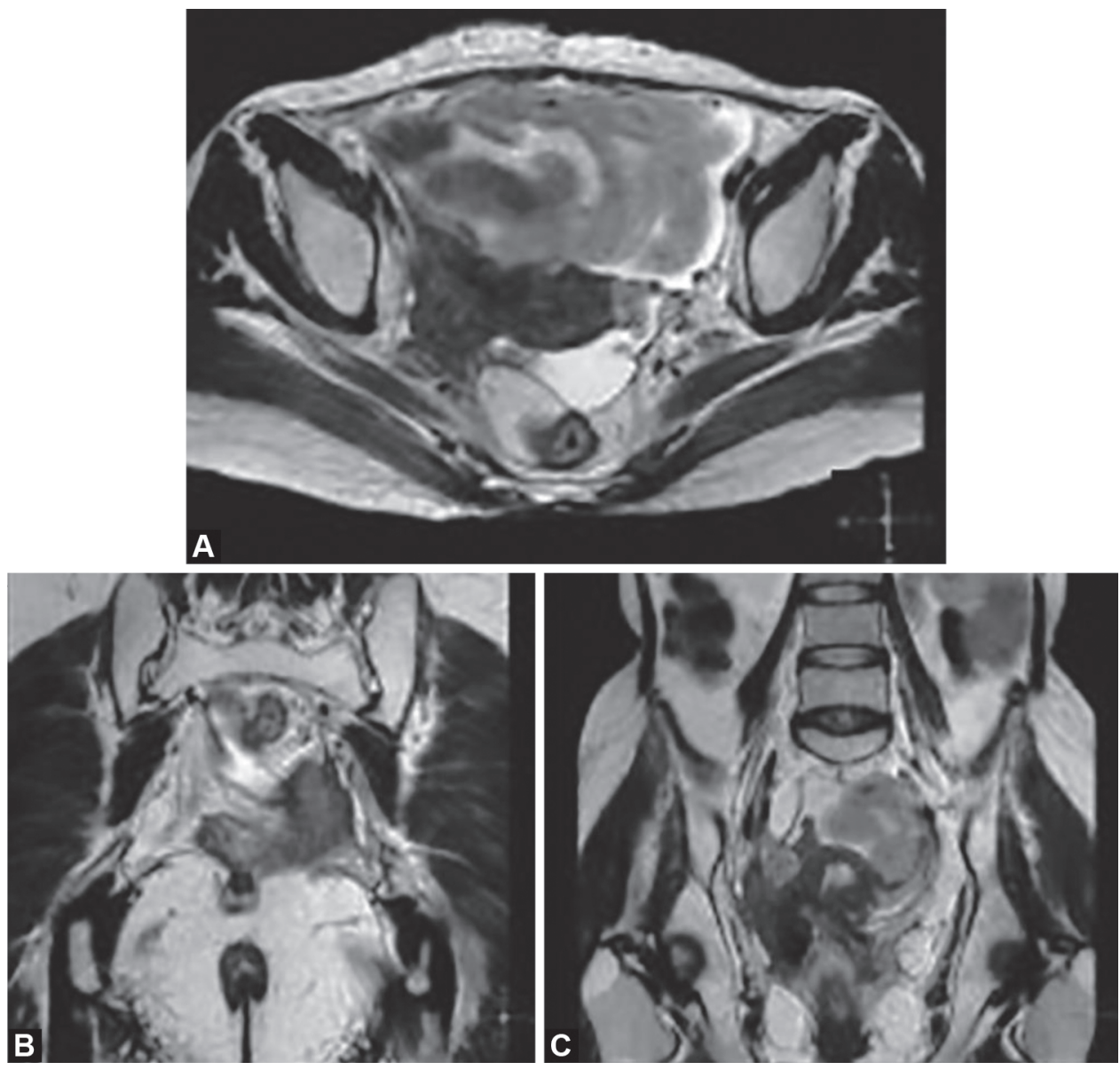

Figs 12A to C: (A) T2W axial; (B and C) T2W coronal

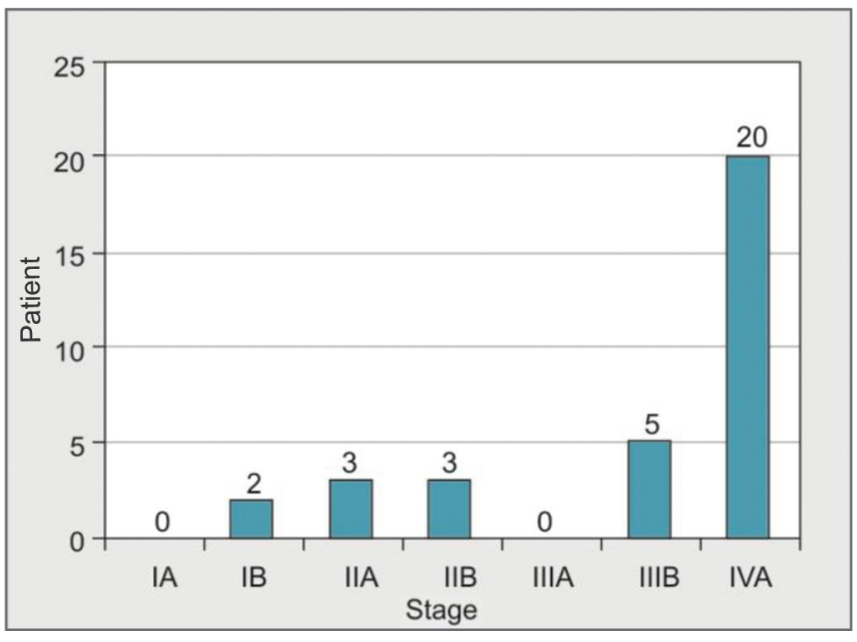

Fig. 13: Graphical representation of stagewise distribution of lymphadenopathy

As we need to compare both studies and to see for any difference if any exists we applied the $X^{2}$ test to the MRI staging and clinical staging.

We found significant difference in clinical and MRI staging with Chi square value of 43.6 and $p$ value $<0.01$ (Table 15).
Table 7: Stagewise distribution of lymphadenopathy

\begin{tabular}{lc}
\hline Stage & No. of patients \\
\hline IA & 0 \\
IB & 2 \\
IIA & 3 \\
IIB & 3 \\
IIIA & 0 \\
IIIB & 5 \\
IVA & 20 \\
Total & 33 \\
\hline
\end{tabular}

$Z$ score demonstrates significant difference in MRI and clinical staging at every $T$ stage (Table 16).

These findings suggest a significant difference in MRI and clinical staging in stages IB, IIB, IIIB, and IVA as a $p$ value $<0.05$, where $n$ is the patient population in each group. The $n$ for MRI was 79 , and $n$ for clinical staging was 83 . There were four patients less in the total patient population of MRI because MRI did not show any mass lesion in these patients who had a clinical diagnosis of stage IA disease.

The $Z$ score (RD) was the highest for stage IIIB and minimum 0.034 for stage IIIA, suggesting that the greatest difference was observed in stage IIIB and no significant difference was seen in stage IIIA, IA and stage IIA. 
Table 8: Unilateral/bilateral iliac lymphadenopathy

\begin{tabular}{lc}
\hline Laterality & No. of patients \\
\hline Unilateral & 19 \\
Bilateral & 9 \\
Total & 28 \\
\hline
\end{tabular}

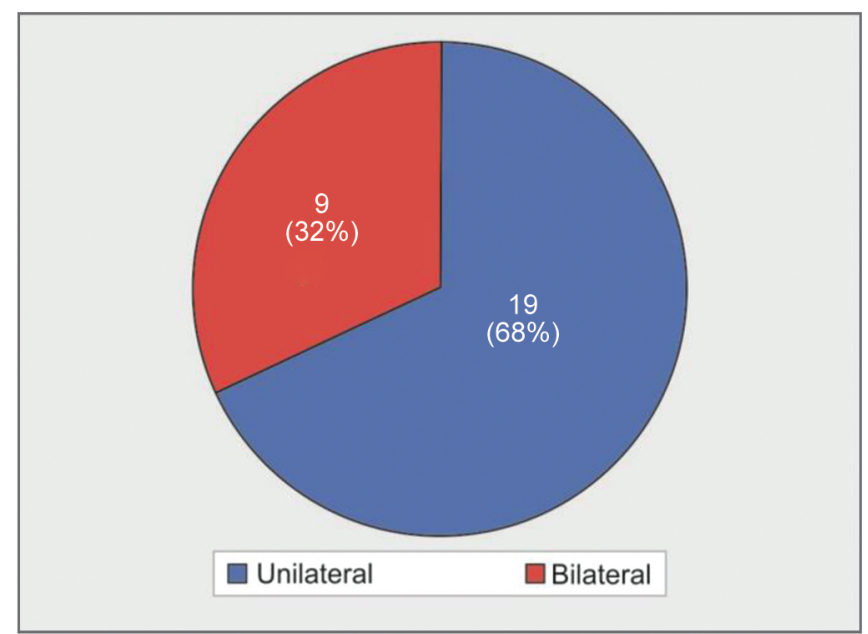

Fig. 14: Laterality of lymphadenopathy

\section{Discussion}

We studied 95 patients with MRI. Eight three subjects were diagnosed with biopsy-proven cervical carcinoma. Twelve patients had suspected recurrence clinically.

We had only 2 cases in the second decade with a steep rise to 18 cases in the 3 rd decade. Then there was a steady increase from 24 cases in the 4th decade to reach a maximum of 30 cases in the 6th decade and a sharp fall in the 7th decade with only 2 cases.

These our findings demonstrate the typical demographic presentation of cervical carcinoma in India, where cervical carcinoma is seen in every age beginning from the reproductive age group.

Maximum no cases were seen in 5th and 6th decade which together consisted of more than $50 \%{ }^{38}$ cases of cervical carcinoma. As the maximum, no of cases were seen in 5th and 6th age group which is also consistent with the natural history of cervical

Table 9: Lymph node region

\begin{tabular}{lrcc}
\hline $\begin{array}{l}\text { Lymph node } \\
\text { region }\end{array}$ & \multicolumn{3}{c}{ No. of patients } \\
\hline Iliac & 28 & 19 & 9 \\
Perirectal & 1 & 0 & 0 \\
Periaortic & 5 & 0 & 0 \\
\hline
\end{tabular}
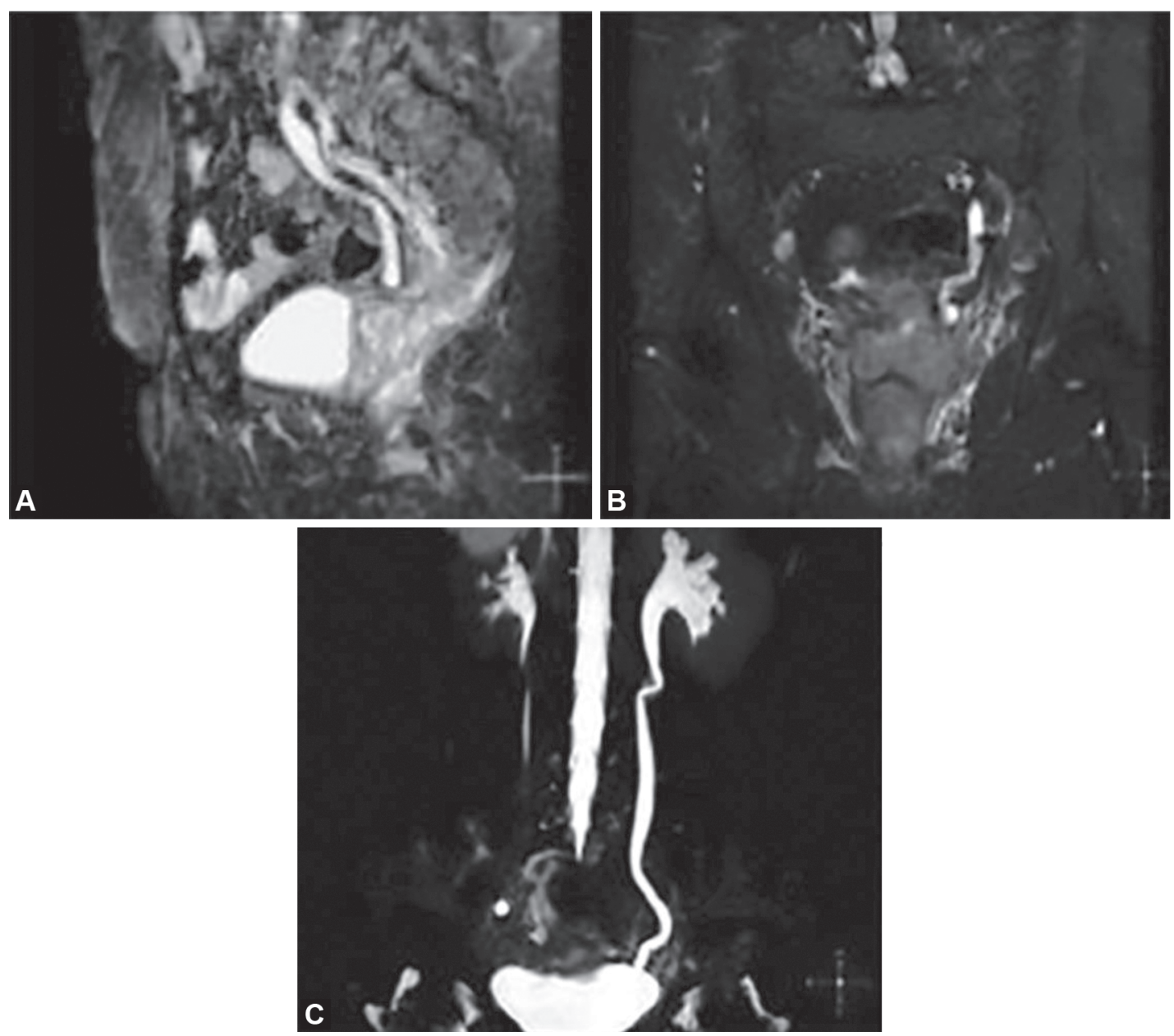

Figs 15A to C: (A) T2W sagittal fat saturation; (B) T2W coronal fat saturation; (C) Coronal static MR urography left-sided hydronephrosis and hydroureter 

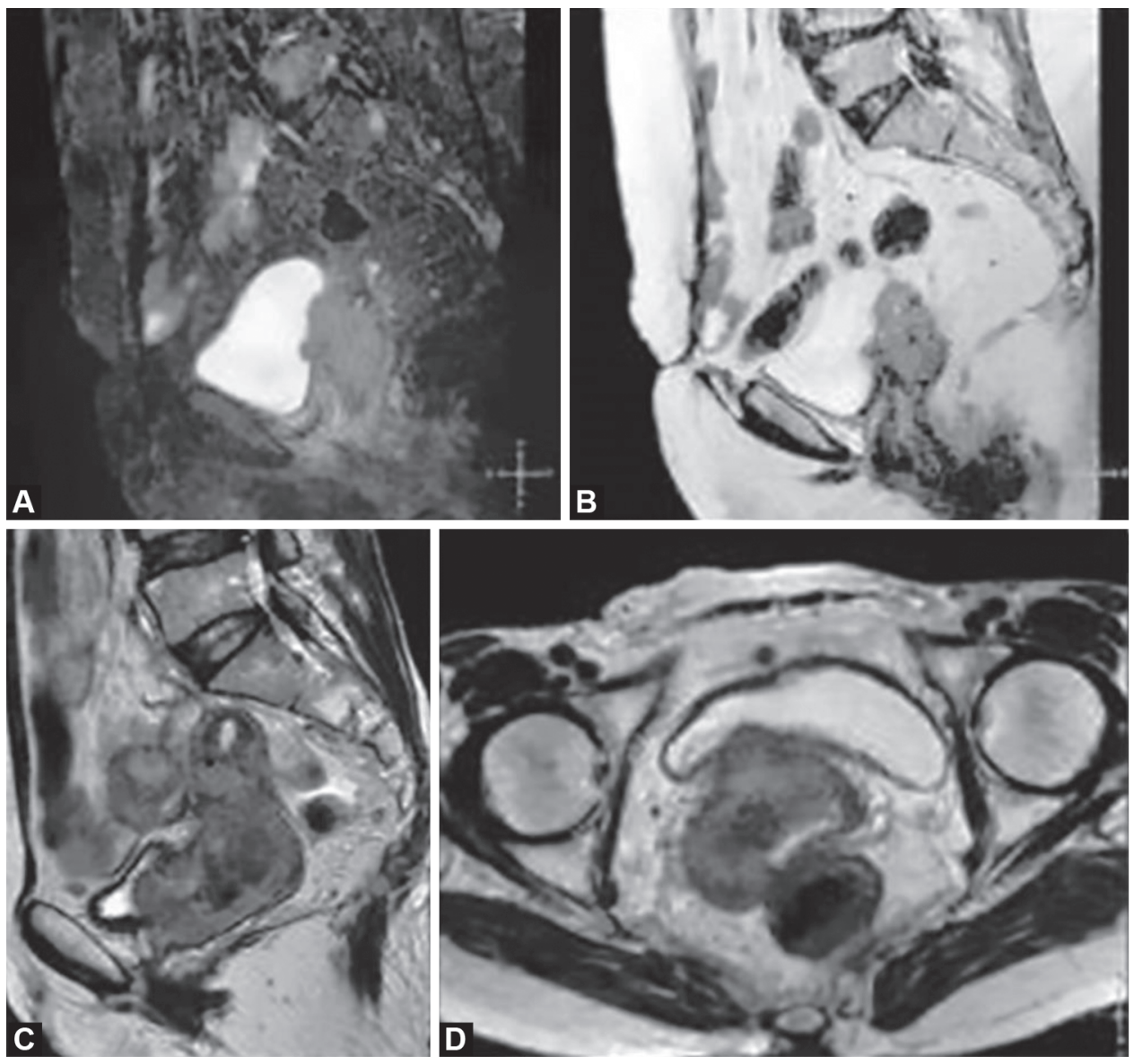

Figs 16A to D: (A) T2W sagittal fat saturation; (B) T2W sagittal; (C) T2W sagittal; (D) T2W axial

Table 10: Stagewise uterine body invasion

\begin{tabular}{lc}
\hline Stage & No. of patients \\
\hline IA & 0 \\
IB & 3 \\
IIA & 1 \\
IIB & 3 \\
IIIA & 0 \\
IIIB & 5 \\
IVA & 14 \\
Total & 26 \\
\hline
\end{tabular}

carcinoma with carcinoma in situ being common in the 3rd decade of age and invasive cervical carcinoma is common in the 5 th decade.

There were maximum no of the patients of cervical carcinoma from stage II disease and it constituted almost $46 \%$ of total patients. The stage IV disease was seen in 20 patients with $25 \%$ of cases. Out of the total 79 cases diagnosed with MRI, stage I and stage III disease represented 32 cases i.e., $29 \%$ of total cases. MRI has diagnosed 36 cases that is almost three times the no of cases it was diagnosed as stage I or stage III disease.

Seki et al. and Yamashita et al. ${ }^{28,39}$ showed that $95 \%$ invasive cervical tumors as the hyperintense area on $\mathrm{T} 2 \mathrm{~W}$ sequence invading low-intensity cervical stroma. We observed similar findings where MRI demonstrated hyperintense area (HIA) on T2W sequences at

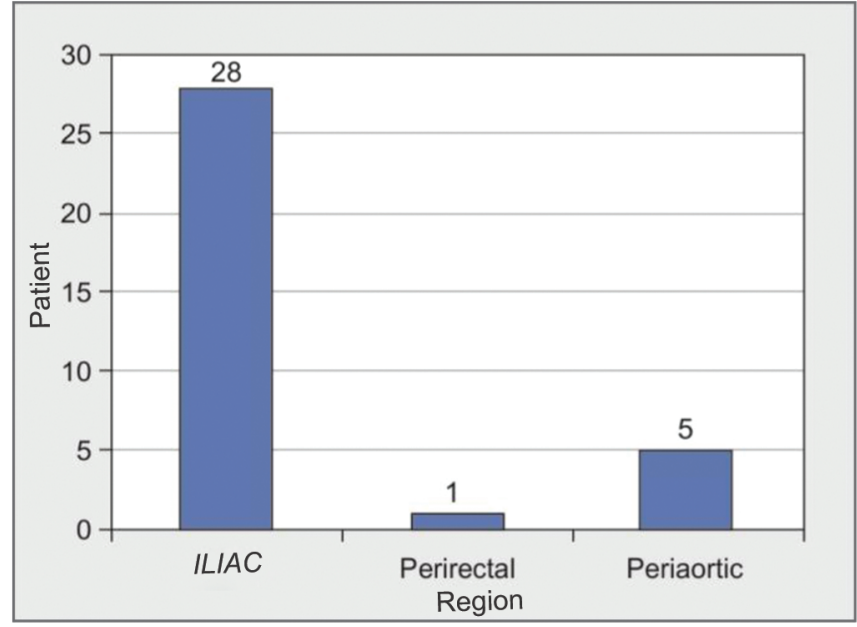

Fig. 17: Distribution of lymphadenopathy

uterine cervix in 79 out of 83 (95\%) patients corresponding to the cervical mass lesion.

The hyperintense area is seen on $\mathrm{T} 2 \mathrm{~W}$ images corresponded to the hyperintense area seen on $\mathrm{T} 2 \mathrm{~W}$ fat saturation images. There was no difference seen between the mass lesion seen on $\mathrm{T} 2 \mathrm{~W}$ images and $\mathrm{T} 2 \mathrm{~W}$ fat saturation images with respect to size and the signal characteristics. Also, the T2W fat saturation images did not add any 

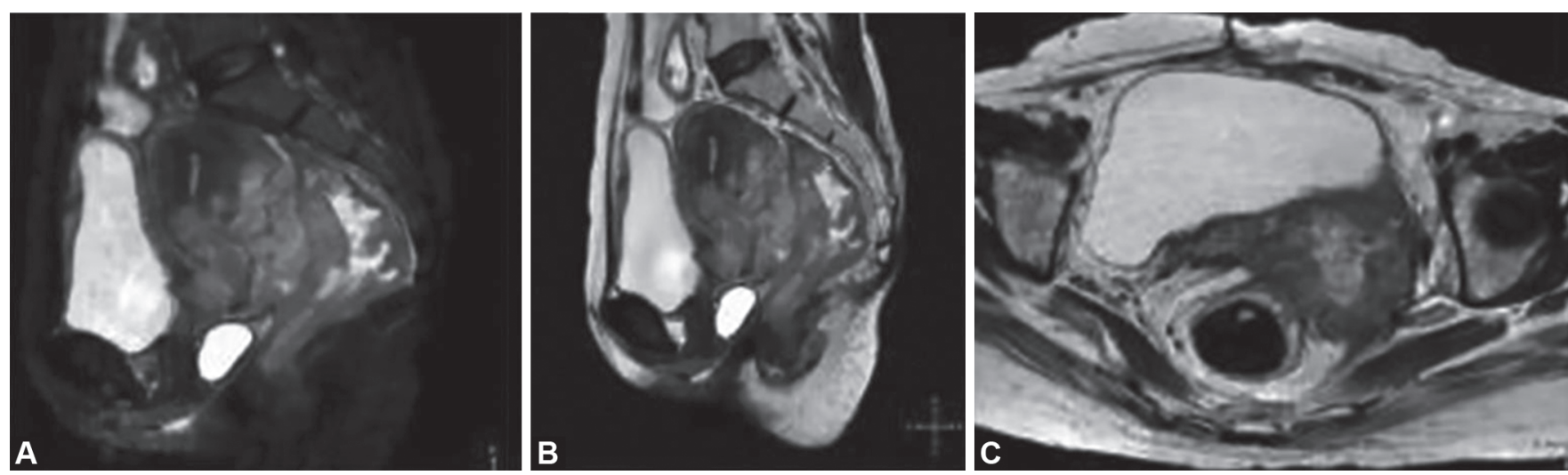

Figs 18A to C: (A) T2W sagittal fat saturation; (B) T2W sagittal; (C) T2W axial

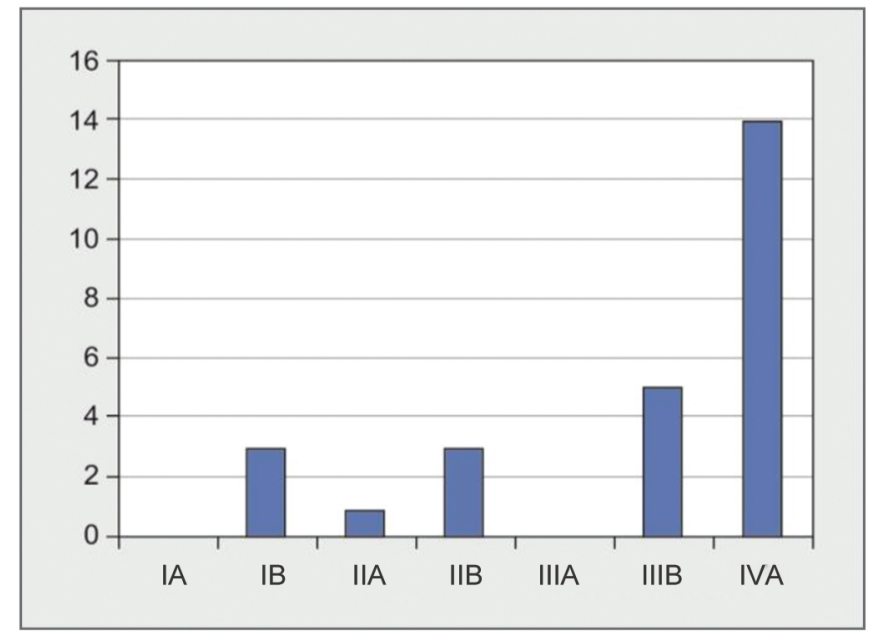

Fig. 19: Stagewise uterine body invasion distribution

significant additional information to the findings obtained from the $\mathrm{T} 2 \mathrm{~W}$ images.

Soyer ${ }^{36}$ retrospective study proved that T2W images are $90 \%$ and specificity $100 \%$ to detect and delineate the tumor. We could demonstrate the mass lesion in 79 of 83 patients (95\%) on T2W images.

Matsubara et al. ${ }^{40}$ which showed that in a study of 62 patients no hyperintense area was seen in any patient of stage 0 or IA and all patients with tumor size of $10 \mathrm{~mm}$ showed hyperintense zone. So on routine T2W MRI images, the diagnosis of the stage IA disease can be made with the use of clinical information.

There was no demonstrable mass lesion seen on MRI or any hyperintense area in the uterine cervical region in 4 out of 83 patients who were clinically diagnosed as stage I carcinoma of the cervix. As there was no visible mass lesion on MRI so these cases were clinically labeled as stage IA disease. Our study findings are similar to Matsubara et al. ${ }^{40}$ study. So 12 stage I patients were labeled as stage IB and no patient was staged as IA with a demonstrable mass on MRI.

Since FIGO in 1994 has delineated the importance of accurate tumor size. Tumor diameter of more than $4 \mathrm{~cm}$ separates the IB1 from IB2. There is a greater degree of awareness towards distinguishing the bulky from non-bulky stage IB tumors. Also, Hope et al. ${ }^{41,42}$ showed that non-bulky stage I tumors can be treated only by surgery and needs no additional therapy. However, treatment for bulky stage I (stage IB2) patients is controversial.

$\mathrm{MRI}$ is more accurate in a bulky tumors group than non-bulky tumor group. Similarly, we also observed 9 cases of stage IB2 which are three times more in comparison to the 3 cases diagnosed as stage IB1 out of total 12 stage IB patients. ${ }^{41}$

Matsubara ${ }^{40}$ proved that axial and coronal planes are best for identifying parametrial invasion. Parametrial invasion is present if the tumor invades the low intensity cervical stromal ring on $\mathrm{T} 2 \mathrm{~W}$ images. We used the same criteria and observed focal invasion of cervical stromal ring in 31 of $38(81 \%)$ patients with parametrial invasion and hence staged as stage IIB. Vaginal invasion is seen in 9 of 38 patients (23\%) so they were staged as stage IIA.

Parametrial invasion decides the stage and management. MR imaging has an accuracy of $95 \%$ for invasive disease IB or higher. Accuracy is $89 \%$ for parametrial invasion on MRI. Presence of intact hypointense cervical stromal ring on T2 weighted images excludes parametrial invasion. ${ }^{9,43-46}$

Subak et al. ${ }^{10}$ in 79 patients showed accuracy $90 \%$ in staging, $94 \%$ in the parametrial invasion.

MRI is shown to have $94 \%$ accuracy in parametrial and vaginal invasion and differentiating between stage I and IIA from stage IIB is $94 \% .{ }^{19,47}$ In our study out of 11 stages III patients, 10 patients had stage IIIB and only I patient had stage IIIA involving the lower vagina.

Matsubara et al. ${ }^{40}$ inferred that coronal planes are useful in detecting parametrial invasion. The axial T2 weighted imaging identifies the parametrial, bladder and rectal invasion. The sagittal planes are the most important in diagnosing the invasion of urinary bladder, vagina, and rectum.

19 of 79 patients had stage IV disease with involvement of urinary bladder and rectum.

Popovich et al. ${ }^{48}$ studied 23 patients with MRI to identify the invasion of the rectal, urinary bladder, pelvic sidewall, and to detect the enlarged lymph nodes with 100\% NPP. MRI can show contiguous tumor invasion where the cystoscopic study may show no abnormality and concluded that MRI provides an accurate means of selecting patients for pelvic exenteration.

Hricak et al. ${ }^{16,49}$ demonstrated that use of MRI as a pretreatment workup reduces the number of procedure and invasive studies such as barium enema, proctoscopy, resulting in substantial cost savings.

According to the FIGO classification stage, IVA disease is defined as tumor invasion of bladder or rectal mucosa, which can be detected by cystoscopy and sigmoidoscopy with the aid of biopsy. If 

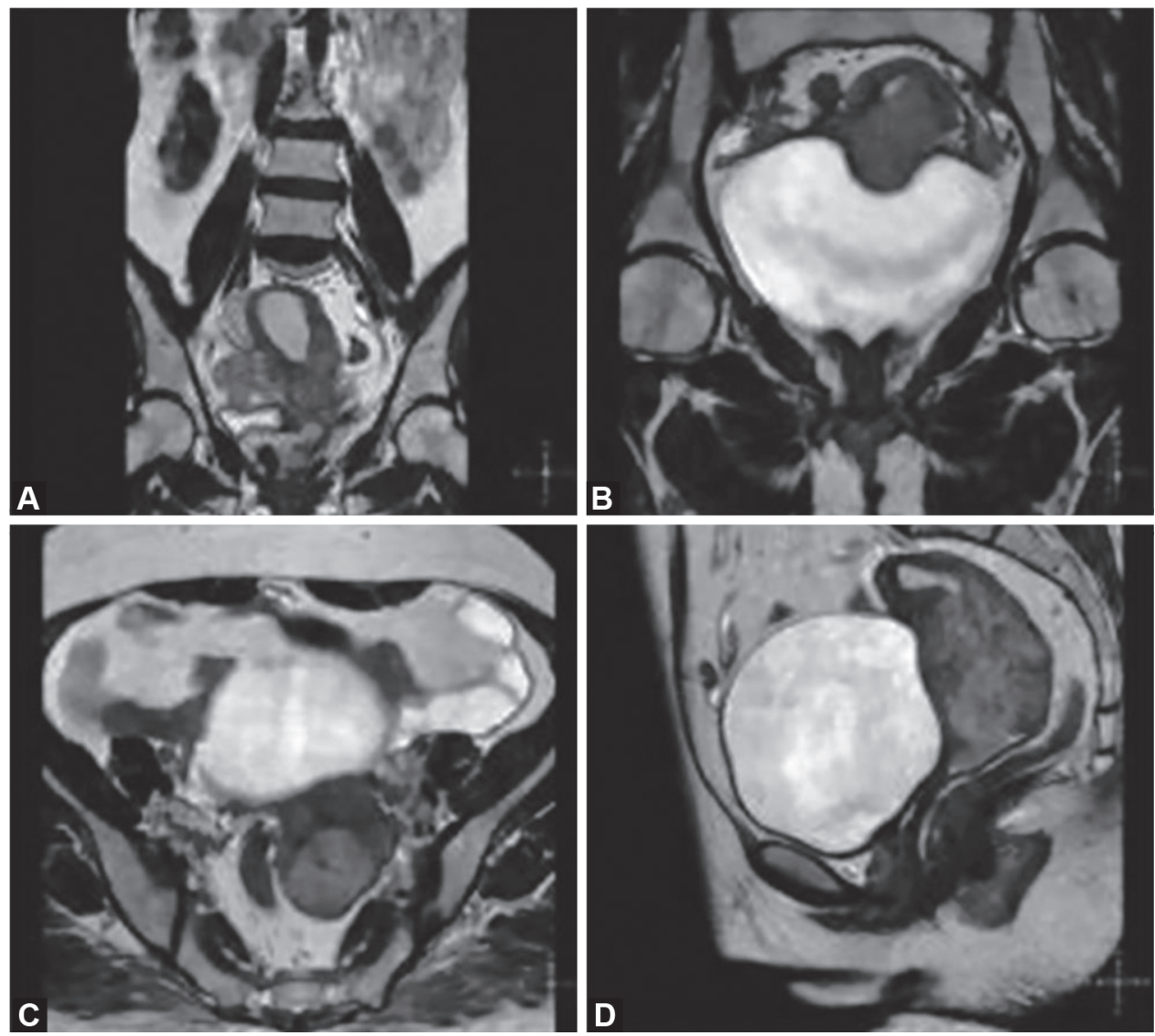

Figs 20A to D: (A) T2W coronal; (B) T2W coronal; (C) T2W axial; (D) T2W sagittal

Table 11: Fistula

\begin{tabular}{ll}
\hline Fistula & No. of patients \\
\hline Rectovaginal & 4 \\
Vesicovaginal & 2 \\
Rectovaginal and vesicovaginal & 1 \\
Total & 7 \\
\hline
\end{tabular}

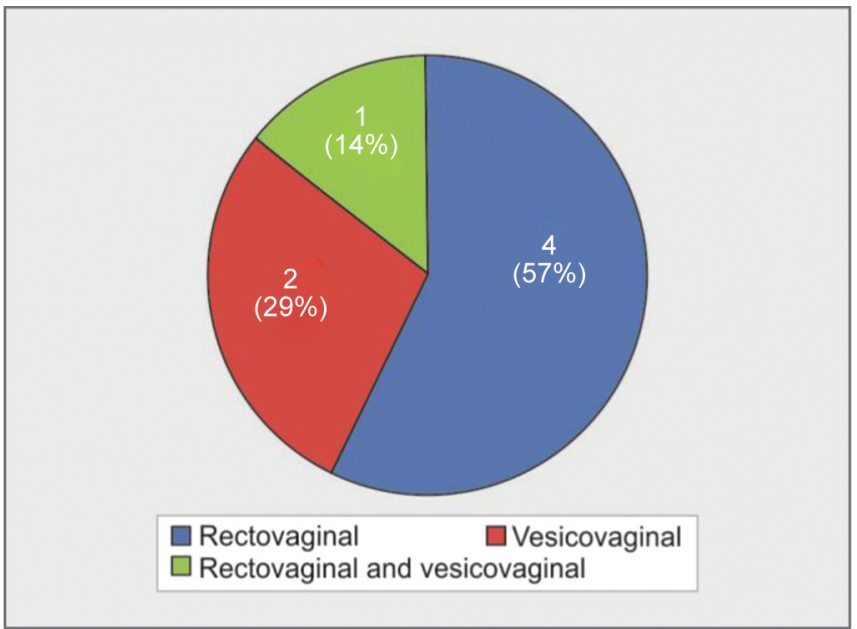

Fig. 21: Types of fistula the serosa or muscular layer is invaded and mucosa is intact, radical hysterectomy is avoided because the bladder or rectum cannot be separated from the cervical mass during surgery.

There are 20 patients who had stage IV disease with involvement of urinary bladder, uterosacral ligament and/or rectum.

Kim et al. ${ }^{35}$ showed that MRI has $83 \%$ sensitivity, $100 \%$ specificity and $99 \%$ accuracy in the vesical invasion. Bladder wall nodularity, irregularity at the posterior bladder wall are suggestive of bladder wall invasion. We used these criteria in 79 out of 83 patients, we observed vesical invasion in 16 of 20 cases of stage IVA.

Many study separately showed high NPP in evaluating invasion of bladder, rectum, pelvic side wall so it is reliable to exclude the patients for cystoscopy, proctoscopy or more invasive investigations and also to exclude the patients considered for pelvic exenteration and laparotomy. Likewise in our study, we excluded 67 of 83 patients who did not require cystoscopy and 66 of 83 patients who did not require the rectosigmoidoscopy and selecting 10 more patients who were not suspected to have bladder and rectal invasion on clinically by a physician required cystoscopy or sigmoidoscopy for same.

So MRI can be used to detect pelvic organ invasion in a noninvasive manner and to select or exclude the patients for cystoscopy or sigmoidoscopy. ${ }^{41}$

The presence of juxta - regional and para-aortic lymph nodes, patient age, tumor size, MRI stage are the most important prognostic factors. ${ }^{50}$ Yang et al. ${ }^{51}$ studied 949 lymph nodes with CT 
Table 12: Clinical staging

\begin{tabular}{lc}
\hline Clinical stage & No. of patients \\
\hline I & 8 \\
II & 12 \\
III & 53 \\
IV & 10 \\
\hline
\end{tabular}

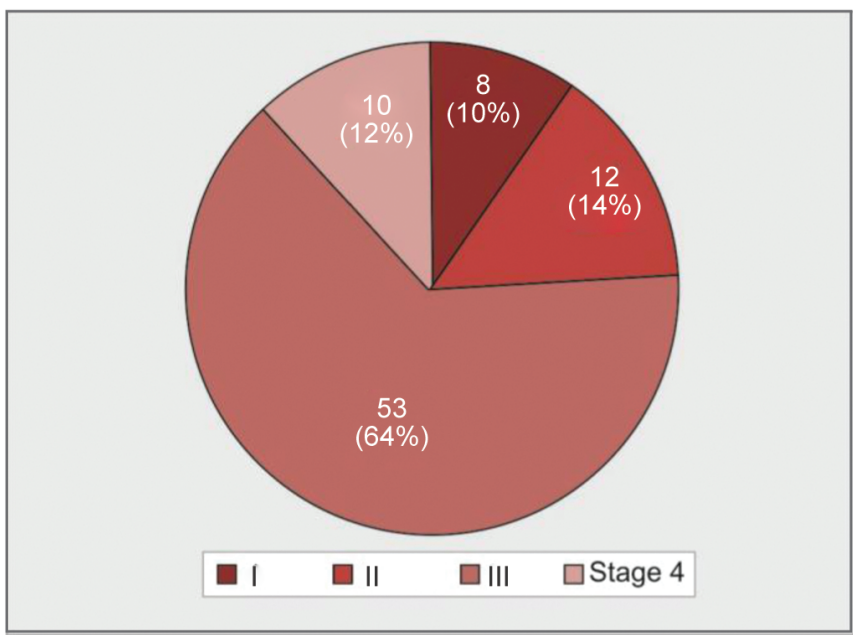

Fig. 22: Clinical stagewise distribution

Table 14: Comparison between MRI and clinical staging

\begin{tabular}{lcc}
\hline Stage & MRI & Clinical \\
\hline IA & 0 & 4 \\
IB & 12 & 4 \\
IIA & 5 & 1 \\
IIB & 31 & 11 \\
IIIA & 1 & 1 \\
IIIB & 10 & 52 \\
IVA & 20 & 10 \\
Total & 79 & 83 \\
\hline
\end{tabular}

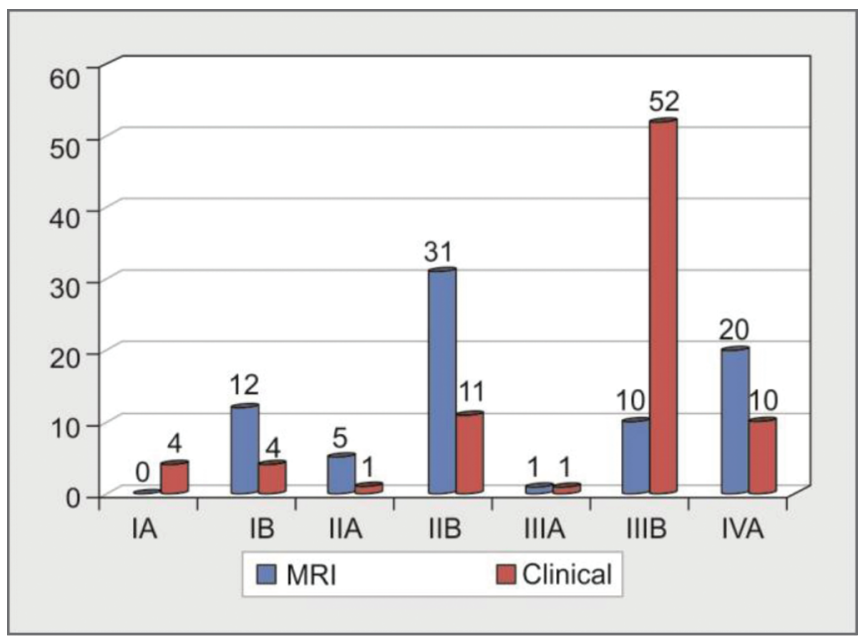

Fig. 24: Comparison of MRI and clinical staging (Graphical representation)
Table 13: Comparison between MRI and clinical staging

\begin{tabular}{llc}
\hline Stage & MRI & Clinical \\
\hline I & 12 & 8 \\
II & 36 & 12 \\
III & 11 & 53 \\
IV & 20 & 10 \\
Total & 79 & 83 \\
\hline
\end{tabular}

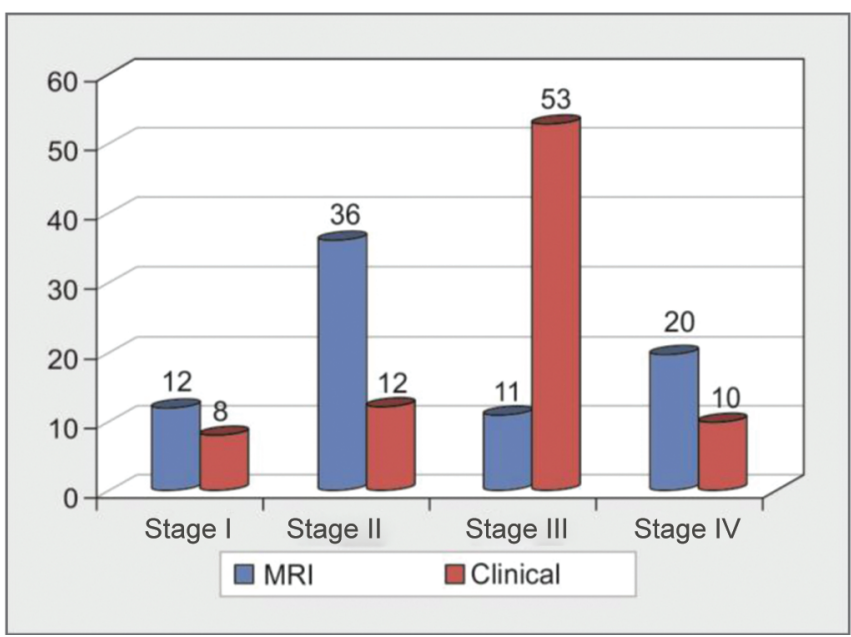

Fig. 23: Comparison between MRI and clinical staging (Graphical representation)

Table 15: Chi-square test

\begin{tabular}{lll}
\hline Stage & $R D$ & $p$ value \\
\hline I & 1.18 & $>0.05$ \\
II & 4.33 & $<0.05$ \\
III & 6.5 & $<0.05$ \\
IV & 2.17 & $<0.05$ \\
$N$ & 79 & 83 \\
\hline Stage & MRI & Clinical \\
\hline I & 12 & 8 \\
II & 36 & 12 \\
III & 11 & 53 \\
IV & 20 & 10 \\
Total & 79 & 83 \\
\hline
\end{tabular}

$X^{2}$ value $=43.6$

$p$ value $=<0.01$

and MRI and compared with surgical findings and histopathological findings with $1 \mathrm{~cm}$ on $\mathrm{CT}$ or MRI as size criterion and showed similar specificity, sensitivity, PPV and NPV. In our study, we used similar criteria and we found 33 of 79 patients having pelvic or periaortic lymphadenopathy of which 20 patients $60 \%$ of patients with lymphadenopathy had stage IV. So there is an increase in the lymphadenopathy with the increase in the stage..$^{38,41}$

Out of total 34 patients (55\%), 19 patients had unilateral iliac lymphadenopathy (26\%) had bilateral lymphadenopathy and only 1 (2\%) patient had perirectal lymphadenopathy, 5 patients (14\%) had periaortic lymphadenopathy. 
Table 16: Z-score test

\begin{tabular}{lcc}
\hline Stage & MRI & Clinical \\
\hline IA & 0 & 4 \\
IB & 12 & 4 \\
IIA & 5 & 1 \\
IIB & 31 & 11 \\
IIIA & 1 & 1 \\
IIIB & 10 & 52 \\
IVA & 20 & 10 \\
Total & 79 & 83 \\
\hline Stage & $R D$ & $p$ value \\
\hline IA & 1.97 & $>0.05$ \\
IB & 2.18 & $<0.05$ \\
IIA & 1.72 & $>0.05$ \\
IIB & 3.77 & $<0.05$ \\
IIIA & 0.034 & $>0.05$ \\
IIIB & 5.75 & $<0.05$ \\
IVA & 2.13 & $<0.05$ \\
$N$ & 79 & 83 \\
\hline
\end{tabular}

\begin{tabular}{llll}
\hline \multicolumn{4}{c}{ MRI protocol } \\
\hline Sequence & TR milliseconds & TE milliseconds & FAT suppression \\
\hline T1 TSE & 613 & 14 & NO \\
T2 TSE & 3500 & 90 & NO \\
T2 FAT SAT TSE & 2476 & 70 & YES \\
MR urography & 8000 & 80 & NA \\
static & & &
\end{tabular}

\begin{tabular}{|c|c|}
\hline Stage & Definition \\
\hline 0 & Carcinoma in situ \\
\hline La & Microinvasive disease \\
\hline IA1 & $\begin{array}{l}\text { Stromal invasion no greater than } 3.0 \mathrm{~mm} \text { in depth and } \\
7.0 \mathrm{~mm} \text { or less in horizontal spread }\end{array}$ \\
\hline IA2 & $\begin{array}{l}\text { Stromal invasion more than } 3.0 \mathrm{~mm} \text { but not more than } \\
5.0 \mathrm{~mm} \text { in depth with a horizontal spread of } 7.0 \mathrm{~mm} \text { or } \\
\text { less }\end{array}$ \\
\hline IB & Clinically visible disease \\
\hline IB1 & $\begin{array}{l}\text { A clinically visible lesion } 4.0 \mathrm{~cm} \text { or less in greatest } \\
\text { dimension }\end{array}$ \\
\hline IB2 & $\begin{array}{l}\text { A clinically visible lesion more than } 4.0 \mathrm{~cm} \text { in greatest } \\
\text { dimension }\end{array}$ \\
\hline IIA & $\begin{array}{l}\text { The tumor invades beyond uterus, but not to the lower } \\
\text { one-third of the vagina, without parametrial invasion }\end{array}$ \\
\hline IIB & The tumor invades beyond the uterus with parametrial \\
\hline IIIA & $\begin{array}{l}\text { Vaginal involvement reaches the lower one-third of the } \\
\text { vaginal canal without extending to the pelvic side wall }\end{array}$ \\
\hline IIIB & $\begin{array}{l}\text { The tumor extends to the pelvic wall or causes } \\
\text { hydronephrosis or a nonfunctioning kidney }\end{array}$ \\
\hline IVA & $\begin{array}{l}\text { The tumor invades the mucosa of the bladder or extends } \\
\text { beyond the true pelvis. }\end{array}$ \\
\hline IVB & Distant metastasis. \\
\hline
\end{tabular}

Uterine body invasion provides important prognostic information in patients undergoing radiotherapy. ${ }^{52}$

Uterine body is seen involved in 26 out of 79 patients which were seen as cervical mass invading the uterine body and 23 of 33 (70\%) patients showing lymphadenopathy also show uterine body invasion suggesting lymph node metastasis is two times commoner with uterine body invasion.

Pelvic lymph node metastasis is commoner with uterine body invasion and predicts increased incidence of lymphadenopathy and poor survival. ${ }^{30,53-58}$

The MRI directly showed ureteric involvement in 20 patients of stage III and stage IV disease. Fifteen patient had direct ureteric invasion. Five patients of stage IV were also showing enlarged iliac lymph nodes involving the lower ureter.

We, after performing MRI staging for every patient, compared the patients in each stage with the clinical staging mainly done by clinical palpation in our institute. ${ }^{59}$

MRI diagnosed 12, 36, 11, 20 cases of stage I, II, III and IV respectively. Clinical assessment detected $8,12,53$ and 10 patients of stage I, II, III and IV, respectively.

After applying the $X^{2}$ test to the MRI staging and clinical staging we got $X^{2}$ value of 43.6 and $p$ value $<0.01$. This depicts a substantial difference between the MRI and the clinical staging.

Then we compared the MRI staging with clinical staging according to individual stages and found significant difference between MRI staging and clinical staging with $p$ value $<0.05$ in stage IB, IIB, IIIB, IVA suggesting that MRI has diagnosed significantly more cases in stage IB, IIB and stage IVA while clinical staging has diagnosed significantly more cases in stage IIIB.

But we could not determine whether MRI staging is better than clinical staging as we could not have a surgical study as a gold standard as done in some other studies..$^{59,60}$

However, many studies in the literature describe the lacunae of the clinical methods relative to the cross-sectional imaging.

Nagell et al. ${ }^{11}$ showed that clinical staging shows an error rate of $17-32 \%$ in stage IB and up to $67 \%$ with stage III and IV disease relative to intraoperative or pathological findings.

Many studies showed in two different studies showed MRI has an accuracy of $77-83 \%$ better than clinical staging. The MRI is more accurate in size and extension of the tumor relative to clinical palpation in inoperable tumors. ${ }^{10,31,46,50,61-63}$

Hricak et al. ${ }^{50}$ calculated the accuracy of MR images in the location of a tumor $91 \%$ for vaginal extension $90 \%$ and parametrial invasion $88 \%$. Pelvic sidewall invasion, urinary bladder, and rectal invasion were accurately excluded in all patients.

Clinical FIGO staging has inherent inaccuracies and low prediction of prognostic factors. MRI offers direct tumor visualization. It is also accurate in predicting the stromal invasion. ${ }^{39,40,50,65-67}$

In our study, we found that there was a significant difference in clinically diagnosed stage IIIB cases and MRI diagnosed stage IIIB cases.

In our institute, the clinicians make a stage IIIB diagnosis when there is thickening of the bilateral parametrial invasion to the lateral pelvic wall on clinical palpation only. MRI findings did not show lateral pelvic wall invasion in most cases. MRI showed direct rectal or bladder wall invasion in other patients.

In patients where clinical findings showed stage IIIB disease, the MRI staging showed 8 patients as stage IB, 4 as IIA, 20 as IIB, and 10 as IVA.

In stage IA, IIA, IIIA, no significant difference was found between the clinical staging and the MRI. This may be because of the inability of conventional MRI to demonstrate the mass lesion in stage IA disease, or a low number of cases in stage IIA, IIIA.

Also, only 3 out of the 10 patients diagnosed as stage IIIB on MRI were having lateral pelvic wall invasion and rest 7 patients 
were having ureteric involvement rather than the lateral pelvic wall invasion.

As described by the study done by Mitchell et al. ${ }^{57}$ showed that MRI is superior in detecting the uterine body involvement relative to clinical methods and CT. The invasion of the uterine body and involvement of lymph nodes is not considered in clinical staging, which is important prognostic factors and well demonstrated on MRI. We found 20 patients of lymphadenopathy associated with uterine invasion and the maximum number of patients of uterine invasion and pelvic lymphadenopathy seen in stage IVA, suggesting that there is increased occurrence of lymphadenopathy with uterine invasion and it increases as the stage increases whereas clinical staging did not consider these important prognostic factors at all.

We used the hypointense signal on all pulse sequences with no demonstrable mall lesion in a patient taken treatment (chemo and radiotherapy) at least 1 year back as a criteria for no recurrent lesion and we studied 12 of 95 patients referred to rule out any recurrent lesion in cervix, at least 1 year after completion of chemo and radiotherapy and $\mathrm{MRI}$ demonstrated hypointense signal intensity at cervical region on all the sequences and we ruled out recurrent lesion in 10 patients. However, in rest of the two two patients, we did not find a similar hypointense signal on all sequences but there was no demonstrable mass lesion on MRI.

So hypointense signal on MRI on all sequences is consistent with post-radiation fibrosis especially 1 year after completion of treatment.

In our study, we demonstrated fistulous tracts between rectum and cervix-vagina, vagina and urinary bladder and both of them together.

The MRI clearly showed seven such fistulae. Four of them were a rectovaginal fistula, two were vesicovaginal and one was a rectovaginal-vesicovaginal fistula. MRI directly shows the hyperintense tract on $\mathrm{T} 2 \mathrm{~W}$ images and also the correct anatomical localization of tract.

As most of our patients were in stage IIB, III, IV where radiotherapy remains modality of choice MRI staging could not be compared with surgical staging.

Clinical staging is inaccurate, depends on subjective methods (palpation) and also excludes the important prognostic factors.

MR imaging demonstrates staging of cervical malignancy accurately. MRI depicts the involvement of important prognostic factors such as lymphadenopathy and uterine body invasion.

There is a significant difference in the staging of cervical carcinoma done by MRI and that of clinical staging with lower accuracy of clinical staging.

MRI is a one-stop investigation to stage the cervical malignancy and can select patients who need more invasive procedures like barium enema, IVP. MRI has the potential to completely change therapy and is an objective means of staging cervical malignancy. MRI should be preferred to see the response to treatment and to rule out recurrence.

So MRI should be considered to be a primary investigation in the staging of cervical malignancy instead as a problem-solving tool.

\section{Summary and Conclusion}

MRI confirms the presence of cervical cancer of all stages except stage IA.

It is effective in the localization of cervical mass lesion and its staging.
It accurately measures size in any given plane and so conventional MRI can distinguish between stage IB1 form stages IB2 accurately.

It demonstrates objective evidence for the staging of cervical cancer.

The significant difference (with $X^{2}$ value 43.6 and $p$ value $<0.01$ ) of exists between MRI staging of cervical carcinoma and clinical staging of cervical carcinoma and this difference may be attributed to inherent inaccuracies of clinical staging.

MRI is a one-stop tool to assess cervical carcinoma.

In India the patients of cervical carcinoma present in late stages so there is the need for more number invasive procedures like examination under anesthesia before final clinical staging is done, MRI can obviate such procedures and can replace them as well.

It can triage patients for cystoscopy and sigmoidoscopy.

Prognostic factors such as lymphadenopathy, uterine body invasion is better evaluated which are not considered in clinical staging and important for patient survival.

MRI can avoid and completely replace the other radiological modalities used in the FIGO system like Barium enema, IVP.

MRI delineates and correctly localizes the fistula and can serve as road map for surgical treatment.

The MRI is not officially incorporated in the FIGO staging system. However, it has been widely accepted for purpose of diagnosis, staging, and follow-up of cervical carcinoma. MRI distinguishes tumors invading the parametrium from that confined to cervix only and also differentiating bulky from non-bulky tumors. Importantly it can serve as a single best modality in staging cervical carcinoma.

Apart from accurate, objective staging, MR imaging is invaluable in the evaluation of essential prognostic factors like the size of the tumor, parametrial invasion, uterine body invasion and lymphadenopathy, last two of which are not considered in FIGO clinical staging.

MR imaging should be used as the preferred imaging modality for staging cervical cancer.

\section{References}

1. Parkin DM, Pisani P, Ferlay J. Global cancer statistics. CA Cancer J Clin 1999;49(1):33-64. DOI: 10.3322/canjclin.49.1.33.

2. Nicolet V, MR Imaging of Cervical Carcinoma: A Practical Staging Approach FOGSI. 2010.

3. Bosch XCSdS FX. 2005 estimates. United Nations' population division world population prospects the 2004 revision, New York. Br J Cancer 2005;98(1):15-21. DOI: 10.1038/sj.bjc.6604146.

4. Castellsagué SdS X, Aguado T, Louie KS, et al., HPV and Cervical Cancer in the World. 2007 Report. WHO/ ICO Information Centre on HPV and Cervical Cancer, HPV Information Centre. IARC GLOBOCON. 2002.

5. Ries LAG, Harkins $D$, Krapcho $M$, et al., ed. SEER Cancer Statistics Review, 1975-2003, National Cancer Institute. Bethesda, MD, SEER Cancer Statistics Review 2006.

6. Castellsagué SdS X, Aguado T, Louie KS, et al., WHO/ICO Information Centre on HPV and Cervical Cancer (HPV Information Centre) cervical cancer -the disease and its burden in India. HPV and Cervical Cancer in the World 2007 Report 2010.

7. Chiang SH, Quek ST. Carcinoma of the cervix: role of MR imaging. Ann Acad Med Singapore 2003;32(4):550-556.

8. Zand $\mathrm{KR}$, Reinhold $\mathrm{C}$, Abe $\mathrm{H}$, et al. Magnetic resonance imaging of the cervix. Cancer Imaging 2007;7(1):69-76. DOI: 10.1102/14707330.2007.0011.

9. Togashi K, Morikawa K, Kataoka ML, et al. Cervical cancer. J Magn Reson Imaging 1998;8(2):391-397. DOI: 10.1002/jmri.1880080219. 
10. Subak LL, Hricak $\mathrm{H}$, Powell $\mathrm{CB}$, et al. Cervical carcinoma: computed tomography and magnetic resonance imaging for preoperative staging. Obstet Gynecol 1995;86(1):43-50. DOI: 10.1016/00297844(95)00109-5.

11. Van Nagell JR,Jr, Roddick JW,Jr, Lowin DM. The staging of cervical cancer: Inevitable discrepancies between clinical staging and pathologic findinges. Am J Obstet Gynecol 1971;110(7):973-978. DOI: 10.1016/0002-9378(71)90551-5.

12. Dargent D, Frobert JL, Beau G. V factor (tumor volume) and T factor (FIGO classification) in the assessment of cervix cancer prognosis: the risk of lymph node spread. Gynecol Oncol 1985;22(1):15-22. DOI: 10.1016/0090-8258(85)90002-2.

13. Swift PS, In: Liebel SAPT, ed. Carcinoma of the uterine cervix. Clinical radiation oncology. Philadelphia, Pa: Saunders; 1998;1998:799-841.

14. Reinhold CGB, Ascher SM. Uterus and cervix Semelka RC, Ascher SM, et al., ed. MRI of the abdomen and pelvis: a text atlas, vol. 1997, New York, NY: Wiley-Liss; 1997. pp. 585-660.

15. McCarthy $\mathrm{SHH}$. The uterus and vagina Higgins $\mathrm{CB}$, Hricak $\mathrm{H}$, Helms CA, ed. Magnetic resonance imaging of the body. 3rd ed., New York, NY: Lippincott-Raven; 1997. pp. 761-814.

16. Hricak H, Powell CB, Yu KK, et al. Invasive cervical carcinoma role of MR imaging in pretreatment work up-cost minimization and diagnostic efficacy analysis radiology magnetic resonance imaging of the abnormal female pelvis. 1996;198(2):403-409. DOI: 10.1148/ radiology.198.2.8596840.

17. Butler $\mathrm{H}$, Bryan $\mathrm{P}$, LiPuma J, et al. Magnetic resonance imaging of the abnormal female pelvis. AJR Am J Roentgenol 1984;143(6):1259-1266. DOI: 10.2214/ajr.143.6.1259.

18. Bies JR, Ellis J, Kopecky K, et al. Assessment of primary gynecologic malignancies: comparison of 0.15-T resistive MRI with CT. AJR Am J Roentgenol 1984;143(6):1249-1257. DOI: 10.2214/ajr.143.6.1249.

19. Bartoli JM. MGARP. Role of X-ray CT and magnetic resonance imaging in the diagnosis of gynecological malignant tumor. Ann Radiol (Paris) 1990;33(4-5):241-247.

20. Michniewicz K, Oellinger J. Diagnostic imaging in invasive cervical carcinoma: MRI, CT, and ultrasonography. Zentralbl Gynakol 2001;123(4):222-228. DOI: 10.1055/s-2001-14784.

21. Vorgias G, Katsoulis M, Argyrou K, et al. Preoperative imaging of primary intra-abdominal gynaecological malignancies. Diagnostic accuracy of CT-scan and MRI. A greek cohort study. Eur J Gynaecol Oncol 2002;23(2):139-144.

22. Cobby M, Browning J, Jones $A$, et al. Magnetic resonance imaging, computed tomography and endosonography in the local staging of carcinoma of the cervix. Br J Radiol 1990;63(753):673-679. DOI: 10.1259/0007-1285-63-753-673.

23. Powell MC, Worthington BS, Sokal M, et al. Magnetic resonance imaging--its application to cervical carcinoma. Br J Obstet Gynaecol 1986;93(12):1276-1285. DOI: 10.1111/j.1471-0528.1986.tb07866.x.

24. Bartoli JM, Moulin G, Di Stefano-Louineau D, et al. Uterine cervix cancers: staging by magnetic resonance imaging. Ann Radiol (Paris) 1990;33(4-5):241-247.

25. Williams MP, Husband JE, Heron CW, et al. Magnetic resonance imaging in recurrent carcinoma of the cervix. Br J Radiol 1989;62(738):544-550. DOI: 10.1259/0007-1285-62-738-544.

26. Sheu M, Chang C, Wang J, et al. MR staging of clinical stage I and Ila cervical carcinoma: a reappraisal of efficacy and pitfalls. Eur J Radiol 2001;38(3):225-231. DOI: 10.1016/s0720-048x(00)00278-3.

27. Özsarlak Ö, Tjalma W, Schepens E, et al. The correlation of preoperative $\mathrm{CT}$, MR imaging, and clinical staging (FIGO) with histopathology findings in primary cervical carcinoma. Eur Radiol 2003;13(10):2338-2345. DOI: 10.1007/s00330-003-1928-2.

28. Seki H, Azumi R, Kimura M, et al. Stromal invasion by carcinoma of the cervix: assessment with dynamic MR imaging. AJR Am J Roentgenol 1997;168(6):1579-1585. DOI: 10.2214/ajr.168.6.9168730.

29. Tsuda K, Murakami T, Kurachi $H$, et al. MR imaging of cervical carcinoma: comparison among $\mathrm{T} 2$-weighted, dynamic, and postcontrast T1-weighted images with histopathological correlation. Abdom Imaging 1997;22(1):103-107. DOI: 10.1007/s002619900151.
30. Perez CA, Camel HM, Askin F, et al. Endometrial extension of carcinoma of the uterine cervix: a prognostic factor that may modify staging. Cancer 1981;48(1):170-180. DOI: 10.1002/10970142(19810701)48:13.0.co;2-0.

31. Martin AJ, Poon CS, Thomas GM, et al. MR evaluation of cervical cancer in hysterectomy specimens: correlation of quantitative T2 measurement and histology. J Magn Reson Imaging 1994;4(6):779786. DOI: $10.1002 /$ jmri.1880040607.

32. Goto M, Okamura S, Ueki M, et al. Evaluation of magnetic resonance imaging in the diagnosis of extension in uterine cervical cancer cases with special attention to imaging planes. Nihon Sanka Fujinka Gakkai Zasshi 1990;42(12):1627-1633.

33. Einspieler R, Ebner F, Hofmann HM, et al. Staging of cervix cancer using MRT. Rofo 1990;152(1):67-70. DOI: 10.1055/s-20081046819.

34. Roy C, Le Bras Y, Mangold L, et al. Small pelvic lymph node metastases: evaluation with MR imaging. Clin Radiol 1997;52(6):437-440. DOI: 10.1016/s0009-9260(97)80004-9.

35. Kim SH, Han MC. Invasion of the urinary bladder by uterine cervical carcinoma: evaluation with MR imaging. AJR Am J Roentgenol 1997;168(2):393-397. DOI: 10.2214/ajr.168.2.9016214.

36. Soyer P, Rigaud C, Masselot J, et al. Evaluation of the role of MRI at 1.5 $\mathrm{T}$ in the staging of the initial extension of cancer of the uterine cervix. J Belge Radiol 1991;74(2):85-90.

37. Scheidler J, Hricak H, Yu KK, et al. Radiological evaluation of lymph node metastases in patients with cervical cancer. a meta-analysis. JAMA 1997;278(13):1096-1101. DOI: 10.1001/ jama.1997.03550130070040.

38. Choi HJ, Kim SH, Seo SS, et al. MRI for pretreatment lymph node staging in uterine cervical cancer. AJR Am J Roentgenol 2006;187(5):W538-W543. DOI: 10.2214/AJR.05.0263.

39. Abe Y, Yamashita Y, Namimoto T, et al. Carcinoma of the uterine cervix. High-resolution turbo spin-echo MR imaging with contrast-enhanced dynamic scanning and T2-weighting. Acta Radiol 1998;39(3):322-326. DOI: 10.1080/02841859809172203.

40. Matsubara M. Clinical significance of magnetic resonance imaging (MRI) in evaluation of the extension of uterine cervical cancer. Nihon Sanka Fujinka Gakkai Zasshi 1993;45(10):1115-1122.

41. Hong KS, Ju W, Choi HJ, et al. Differential diagnostic performance of magnetic resonance imaging in the detection of lymph node metastases according to the tumor size in early-stage cervical cancer patients. Int J Gynecol Cancer 2010;20(5):841-846. DOI: 10.1111/ IGC.0b013e3181db5140.

42. Hope AJ, Saha P, Grigsby PW. FDG-PET in carcinoma of the uterine cervix with endometrial extension. Cancer 2006;106(1):196-200. DOI: 10.1002/cncr.21573.

43. Kim SH, Choi BI, Lee HP, et al. Uterine cervical carcinoma: comparison of CT and MR findings. Radiology 1990;175(1):45-51. DOI: 10.1148/ radiology.175.1.2315503.

44. Sironi S, Belloni C, Taccagni L, et al. Invasive carcinoma of the cervix uteri (stage IB-IIB): evaluation using magnetic resonance. Radiol Med 1990;80(3):314-320.

45. Sironi S, Belloni C, Taccagni GL, et al. Carcinoma of the cervix: value of MR imaging in detecting parametrial involvement. AJR Am J Roentgenol 1991;156(4):753-756. DOI: 10.2214/ajr.156.4.2003441.

46. Brunschwig $A$. The surgical treatment of cancer of the cervix: stage I and II. Am J Roentgenol Radium Ther Nucl Med 1968;102(1):147-151. DOI: 10.2214/ajr.102.1.147.

47. Sheu MH, Chang CY, Wang JH, et al. Cervical carcinoma: assessment of parametrial invasion and lymph node metastasis with magnetic resonance imaging. Zhonghua Yi Xue Za Zhi (Taipei) 2000;63(8):634640.

48. Popovich MJ, Hricak $H$, Sugimura $K$, et al. The role of MR imaging in determining surgical eligibility for pelvic exenteration. AJR Am J Roentgenol 1993;160(3):525-531. DOI: 10.2214/ajr.160.3.8430546.

49. Hricak H, Lacey CG, Sandles LG, et al. Invasive cervical carcinoma: comparison of MR imaging and surgical findings. Radiology 1988;166(3):623-631. DOI: 10.1148/radiology.166.3.3340756. 
50. Hricak H, Quivey JM, Campos Z, et al. Carcinoma of the cervix: predictive value of clinical and magnetic resonance (MR) imaging assessment of prognostic factors. Int J Radiat Oncol Biol Phys 1993;27(4):791-801. DOI: 10.1016/0360-3016(93)90451-z.

51. Yang WT, Lam WW, Yu MY, et al. Comparison of dynamic helical CT and dynamic MR imaging in the evaluation of pelvic lymph nodes in cervical carcinoma. AJR Am J Roentgenol 2000;175(3):759-766. DOI: 10.2214/ajr.175.3.1750759.

52. Sala E, Wakely S, Senior E, et al. MRI of malignant neoplasms of the uterine corpus and cervix. AJR Am J Roentgenol 2007;188(6): 1577-1587. DOI: 10.2214/AJR.06.1196.

53. Chung $\mathrm{HH}$, Kang KW, Cho JY, et al. Role of magnetic resonance imaging and positron emission tomography/computed tomography in preoperative lymph node detection of uterine cervical cancer. Am J Obstet Gynecol 2010;203(2):156.e1-5. DOI: 10.1016/j.ajog.2010. 02.041.

54. Narayan K, McKenzie AF, Hicks RJ, et al. Relation between FIGO stage, primary tumor volume, and presence of lymph node metastases in cervical cancer patients referred for radiotherapy. Int J Gynecol Cancer 2003;13(5):657-663. DOI: 10.1136/ijgc-00009577-20030900000014.

55. Noguchi H, Shiozawa I, Kitahara T, et al. Uterine body invasion of carcinoma of the uterine cervix as seen from surgical specimens. Gynecol Oncol 1988;30(2):173-182. DOI: 10.1016/0090-8258(88) 90021-2.

56. Averette $\mathrm{HE}$, Ford $\mathrm{JH}, \mathrm{Jr}$, Dudan $\mathrm{RC}$, et al. Staging of cervical cancer. Clin Obstet Gynecol 1975;18(3):215-232. DOI: 10.1097/00003081197509000-00023.

57. Mitchell DG, Snyder B, Coakley F, et al. Early invasive cervical cancer: Tumor delineation by magnetic resonance imaging, computed tomography, and clinical examination, verified by pathologic results, in the ACRIN 6651/GOG 183 intergroup study. J Clin Oncol 2006;24(36):5687-5694. DOI: 10.1200/JCO.2006.07.4799.

58. Iyer RB, Balachandran A, Devine CE. PET/CT and cross sectional imaging of gynecologic malignancy. Cancer Imaging 2007;7 Spec
No A(Special issue A):S130-S138. DOI: 10.1102/1470-7330.2007. 9015.

59. Mitchell DG, Snyder B, Coakley F, et al. Early invasive cervical cancer: MRI and CT predictors of lymphatic metastases in the ACRIN 6651/ GOG 183 intergroup study. Gynecol Oncol 2009;112(1):95-103. DOI: 10.1016/j.ygyno.2008.10.005.

60. Choi SH, Kim SH, Choi HJ, et al. Preoperative magnetic resonance imaging staging of uterine cervical carcinoma: results of prospective study. J Comput Assist Tomogr 2004;28(5):620-627. DOI: 10.1097/01. rct.0000138007.77725.0a.

61. Heyman J, Kottmeier HL, Segerdahl CO. An investigation of the reliability of stage-grouping in cancer of the uterine cervix. Acta Obstet Gynecol Scand 1953;32(1):65-79. DOI: 10.3109/00016345309157564.

62. Burghardt E, Hofmann HM, Ebner F, et al. Magnetic resonance imaging in cervical cancer: a basis for objective classification. Gynecol Oncol 1989;33(1):61-67. DOI: 10.1016/0090-8258(89)90604-5.

63. Mayr NA, Yuh WTC, Zheng J, et al. Tumor size evaluated by pelvic examination compared with 3-D quantitative analysis in the prediction of outcome for cervical cancer. Int J Radiat Oncol Biol Phys 1997;39(2):395-404. DOI: 10.1016/s0360-3016(97)00318-0.

64. Ho CM, Chien TY, Jeng CM, et al. Staging of cervical cancer: comparison between magnetic resonance imaging, computed tomography and pelvic examination under anesthesia. J Formos Med Assoc 1992;91(10):982-990.

65. Hawnaur JM, Johnson RJ, Buckley $\mathrm{CH}$, et al. Staging, volume estimation and assessment of nodal status in carcinoma of the cervix: comparison of magnetic resonance imaging with surgical findings. Clin Radiol 1994;49(7):443-452. DOI: 10.1016/s0009-9260(05)81738-6.

66. $\mathrm{Kim} \mathrm{SH}, \mathrm{Choi} \mathrm{BI}, \mathrm{Han} \mathrm{JK}$, et al. Preoperative staging of uterine cervical carcinoma: comparison of CT and MRI in 99 patients. J Comput Assist Tomogr 1993;17(4):633-640. DOI: 10.1097/00004728-19930700000022.

67. Haldemann RC, Krestin GP, Marincek B. Magnetic resonance tomography in malignant genital tumors. Schweiz Med Wochenschr 1992;122(19):719-726. 